HOW DO PEOPLE PLAN TO NEGOTIATE?

DAI LE

Business School, University of Queensland

e-mail: dai.le@uq.net.au

DAISUNG JANG

Business School, University of Queensland

e-mail: d.jang@uq.edu.au 


\title{
How Do People Plan to Negotiate?
}

\author{
ABSTRACT \\ Planning is critical for negotiation success as it facilitates obtaining superior outcomes. However, \\ little empirically is known about what people do to plan. We offer an initial exploration of the \\ topic, with the aim of inspiring greater research attention to the topic. We approach the question \\ from an individual differences perspective, since planning phase places greater emphasis on \\ individual action. We explored how the Big Five personality factors and gender predict \\ preference and search for information that facilitates efforts to claim value, create value, and \\ manage relationships. In Study 1, we used a survey method to elicit preferences. Extraversion \\ and conscientiousness predicted preference for information that would help to claim value, and \\ agreeableness predicted preference for information that would help to manage relationships. \\ Women preferred value creating information. In Studies 2, 3, and 4, we examined search \\ behavior using the Mouselab paradigm (Johnson, Payne, Bettman, \& Schkade, 1989). A different \\ pattern of relationships emerged. When the search task was complex, agreeableness predicted \\ how extensively people searched for information. When tasks were more constrained, we \\ detected fewer relationships between individual differences and search behavior.
}




\section{INTRODUCTION}

"I don't think I have to prepare very much." (Donald Trump, 2018)

The former US president made this statement in the lead-up to his summit with the North Korean leader in 2018, on the topic of the denuclearization of the Korean peninsula (Allen \& Clark, 2018). It was indicative of an improvisational approach. Media reports suggested he consulted little with national security staff, and a week before the event, had not held a cabinet level meeting to discuss the issue (Johnson, 2018). The former president stated that he would plan on his flight to the summit, bringing 15 boxes of material with him (McKelvey, 2018). This contrasts with approaches by other presidents, who took months, if not years to plan such events (McKelvey, 2018). Further indicative of an improvisational approach was that high ranking officials, including the former Secretary of State Mike Pompeo, could not define what denuclearization meant, and there were no clear goals set for the summit (Toosi, 2018). The subsequent summits in Singapore and Hanoi ended with an impasse (Sanger \& Wong, 2019).

In contrast to the approach taken by the former president, planning has been emphasized as a critical element of effective negotiations by both practitioners and scholarly researchers. Both groups outline many actions negotiators should engage in before the first offer is made (American Bar Association, 2009; Kennan \& Mearsheimer, 2012; McMains \& Mullins, 2013; Odell, 2000; Rackham, 1988; Schneider \& Honeyman, 2006; Tibergien \& Dahl, 2006). For example, negotiators with information about their counterpart's alternatives claim a greater share of value (Lewicki \& Litterer, 1985).

Despite its importance, planning has received little empirical focus. Although Barley (1991) and Pruitt and Carnevale (1993) indicated a need for research on the topic, it has received 
little attention. A recent review of 330 negotiation studies revealed that only $7 \%$ variables measured the planning phase (Jang, Elfenbein, \& Bottom, 2018), and we are not aware of a study dedicated to empirically examining negotiation planning. We undertake an initial effort to do so and take an individual differences approach to studying planning behavior and generating initial insights. We additionally aim to discuss characteristics and complications to the planning phase, thereby opening up opportunities for additional inquiry.

\section{The Planning Phase}

Despite the stereotype that negotiation begins with the first offer, descriptions from the field show negotiators engage in considerable planning activities. Indeed, experienced diplomats can spend up to $75 \%$ of their time planning to negotiate (Zartman, 2006). Likewise, in both industrial relations disputes in a developed economy and in small-scale societies, parties also spend considerable time and effort defining when and where to negotiate, the issues to be resolved, as well as the limits of the issues under discussion (Gulliver, 1979). In legal contexts, parties engage in efforts to research, document evidence, forecast future developments, estimate the dollar value of the case, and decide where and when to bargain (Williams, 1985). Thus, it is no surprise that expert practitioners regard planning skills as central to effective negotiation (Roloff, Putnam, \& Anastasiou, 2003). Consistent with observations in the field and prior definitions (e.g., Jang et al., 2018; Pruitt \& Carnevale, 1993), we define planning as a set of activities that occur before the first offer which facilitate securing valuable outcomes from negotiation (Hayes-Roth \& Hayes-Roth, 1979).

Despite the lack of empirical studies, theorists have identified multiple dimensions of effective planning. Grounding their theory on a mix of literature to date and of practical wisdom, Peterson and Lucas (2001) identified four types of actions, namely intelligence gathering, 
formulation, strategy development, and preparation. Intelligence gathering involves gathering, sorting, evaluating, and analyzing data (Schultz, Collins, \& McCulloch, 1994). Potential actions in this category can include identifying alternatives (Fisher, Ury, \& Patton, 2011; Pinkley et al., 2019), calculating the importance of specific issues in relation to each other (i.e., multi-attribute valuation (Keeney \& Raiffa, 1991), and considering the ways in which deadlines can impact the process (Moore, 2004). Formulation involves using the intelligence to develop bargaining objectives, anticipate the counterpart's plan, and specify parameters for each of the negotiated issues. Specific examples include setting high and specific targets (Zetik \& Stuhlmacher, 2002) and thinking about the counterpart's incentives (Kerr, 1975). Strategy development concerns consolidating goals and action sequences that have been developed while formulating into a cohesive plan (Quinn, 1980). Examples include strategic planning of concessions (Hilty \& Carnevale, 1993) as well as designing or selecting a bargaining process that maximizes desired outcomes, such as proposing a single text negotiation (Raiffa, 1982). Preparation involves rehearsal of tactics at the negotiation table as well practicing what will be said. Examples of such actions can include plans to deflect questions (Bitterly \& Schweitzer, 2020), or to plans to ask questions that uncover barriers to agreement, and to create or claim value (Fisher et al., 2011).

However, we know little about how people engage in these kinds of planning activities and the factors affect them. Most of the prescriptive texts and empirical findings cited above are based on insights gained from interventions imposed during the bargaining process. Negotiation research has not achieved a descriptive understanding of how people behave in the planning phase. To furnish the literature with initial data and insights about negotiation planning behavior, we focused on exploring how people engage in the initial steps of intelligence gathering. We do so because intelligence gathering is often the first step and could serve as the foundation for the 
other steps in the planning process. In particular, we focus on information evaluation and search. Placing import on specific kinds of information recognizes its impact on the process, and leads to action on its basis (Ajzen, 1991). Likewise, searching for particular information should lead to a greater probability of its use later in the process. This leads to the question of what negotiators value as outcomes from the negotiation process, which we discuss in the next section.

\section{Valued Outcomes in Negotiation}

Negotiators value three distinct outcomes: value claimed, value created, and the relationship between parties (Curhan, Elfenbein, \& Xu, 2006; Gelfand, Major, Raver, Nishii, \& O’Brien, 2006; Lax \& Sebenius, 2006). Value claiming represents one's share of the resource pool. Negotiators can plan to claim more value by having superior alternatives to negotiation (Fisher et al., 2011; Raiffa, 1982) and developing superior arguments to present to the counterpart (Roloff et al., 2003). They can also attempt to gain insights into the counterpart's positions and alternatives (Barry \& Friedman, 1998; Sharma, Bottom, \& Elfenbein, 2013).

Value creation represents the creation of additional value and the possibility of increasing the resource pool (Gray, 1989; Walton \& McKersie, 1991). Negotiators can plan to create value by attempting to find out about additional opportunities with the counterpart (e.g., negotiating an additional issue) and obtaining information about differences that can be leveraged to generate value (Lax \& Sebenius, 2006).

Negotiators also value having a relationship with the counterpart. Surveys show that negotiators value the relationship formed between parties as an outcome in its own right (Curhan et al., 2006). Formed relationships are important for other reasons, because people often renegotiate agreements, necessitating cooperation beyond attaining agreement, such as companies in a joint project or supplier relationships (Mayer \& Argyres, 2004). Alternatively, 
negotiators belong in a community where a history of past exchange informs future actions (Greenhalgh \& Chapman, 1998). Similarly, impressions formed at the negotiating table can affect the longevity of employment relations (Curhan, Elfenbein, \& Kilduff, 2009). Thus, prior experience with a counterpart (Mislin, Boumgarden, Jang, \& Bottom, 2015), or even rumors about a counterpart's conduct can be informative (Tinsley, O'Connor, \& Sullivan, 2002). As a result, achieving insights into the counterpart's prior conduct and personality can facilitate efforts to manage the relationship during the bargaining phase.

Claiming value, creating value, and relationships comprise common sources of value for negotiators. Thus, we focus on how people evaluate and search for these kinds of information. We next discuss how the characteristics of the planning phase suggest individual differences to be informative of planning behavior.

\section{Planning and Individual Differences}

Planning differs in important ways from the bargaining phase. Bargaining is a fundamentally interpersonal activity. Bargaining has been likened to a dance, where parties engage in a sequence of behaviors (Adair \& Brett, 2005). That sequence can involve making offers, asking questions, and attempting to solve problems. Such actions from the counterpart require response in a short timeframe. In contrast, planning does not require interaction with a counterpart that is often perceived to competitive (Thompson \& Hastie, 1990). Negotiators can read documents, determine, and prioritize their interests, and plan alternative courses of action with little or no interaction with others. For this reason, we reason individual differences to be a substantial factor in explaining variability of planning behavior.

Individual differences should predict planning behavior. Individual differences studied in negotiation comprise factors such as age, gender, personality, culture, experience, and cognitive 
ability (Stuhlmacher \& Adair, 2011). Each of these and many other individual differences factors may play a role in negotiation planning, and much remains to be discovered about their role in the planning process. Future research should investigate how a wide range of individual difference factors, both in isolation and in combination affects planning. But as an initial step, we focused on personality and gender because both are also likely to predict planning behavior. Outside the negotiation domain, personality predicted aspects of planning for late stage life care (Sorensen, Duberstein, Chapman, Lyness, \& Pinquart, 2008). Personality also predicted consequential outcomes in various areas of life that demand considerable planning skills, including asset accumulation (Letkiewicz \& Fox, 2014) and career progression (Rogers, Creed, \& Glendon, 2008). Similarly, gender predicted planning behavior as well. Men and women adopted different perspectives and approaches to retirement planning, with men spending significantly more time than women in planning for their retirement (Glass \& Kilpatrick, 1998; Jacobs-Lawson, Hershey, \& Neukam, 2004; Quick \& Moen, 1998; Simmons \& Betschild, 2001). In the field of educational psychology, girls aged between five to seventeen scored higher than boys on the planning scales of the Cognitive Assessment System, a validated measure of cognitive ability (Bardos, Naglieri, \& Prewett, 1992; Naglieri \& Rojahn, 2001; Warrick \& Naglieri, 1993).

\section{The Role of Personality and Gender on Information Evaluation and Search}

We adopted the Big Five model in considering personality. The Big Five represents a comprehensive model of personality (Costa \& McCrae, 1992b) and has been used to study individual differences in negotiation research (Sharma et al., 2013). The model comprises five distinct factors, namely extraversion, agreeableness, conscientiousness, neuroticism, and 
openness to experience. Below we discuss each of the factors and their relevance to negotiation behavior in existing research.

Extraversion reflects individuals' tendencies to be assertive, gregarious, and sociable (Costa \& McCrae, 1992a). They tend to perform better in jobs that involve considerable interpersonal interactions (Barrick \& Mount, 1991; Mount, Barrick, \& Stewart, 1998). However, it was found to be detrimental to claiming value in distributive negotiations because it led to greater information sharing about preferences and alternatives to agreement (Barry \& Friedman, 1998; Dimotakis, Conlon, \& Ilies, 2012). In contrast, the trait facilitates integrative negotiation as it is positively associated with trust, information exchange, and discovery of tradeoffs (Barry \& Friedman, 1998; Ma \& Jaeger, 2005).

Agreeableness is associated with altruism, generosity, warmth, and cooperativeness (Costa \& McCrae, 1992a; John \& Srivastava, 1999). The trait is negatively associated with conflict, challenging others' ideas, and participating in competitive tasks (Graziano, JensenCampbell, \& Hair, 1996). Consistent with this, agreeableness was found to be associated with under-performance in distributive negotiation (Barry \& Friedman, 1998; Dimotakis et al., 2012). Agreeableness is associated with greater concern for relationships with and the interests of others, as it predicts greater concessions and accommodation of the counterpart demands at own expense (Barry \& Friedman, 1998; Cable \& Judge, 2003; De Dreu \& Van Lange, 1995).

Conscientiousness reflects individuals' tendencies to be achievement-oriented and taskfocused (McCrae \& John, 1992). The trait is more closely associated with goal accomplishment than socioemotional involvement (Aronoff \& Wilson, 2014) and creativity (Feist, 1998). This trait is associated with higher lifetime earnings (Gensowski, 2018) and asset accumulation (Letkiewicz \& Fox, 2014). Surprisingly, conscientiousness has not appeared to influence 
individual's performance in the bargaining phase (Barry \& Friedman, 1998; Sharma et al., 2013). This might be attributed to the limited planning and preparation opportunities in most of the negotiation research (Elfenbein, 2015).

Neuroticism reflects the tendency to experience negative emotions (Costa \& McCrae, 1992a; John \& Srivastava, 1999). Uncertainty associated with negotiations could trigger neurotic people to experience negative emotions (Sharma et al., 2013). Neuroticism is also associated with higher face threat sensitivity, which leads to more impasses and less joint value during bargaining (White, Tynan, Galinsky, \& Thompson, 2004). Consistent with this, neuroticism predicts competitive behaviors and deploying more exploitative tactics to elicit concessions (Alexander, Schul, \& McCorkle, 1994; Carnevale \& De Dreu, 2006; Tedeschi, Burrill, \& Gahagan, 1969).

Openness reflects a tendency to be curious, open-minded, imaginative, and creative (Costa \& McCrae, 1992b). In negotiation, the trait leads to less "fixed pie" bargaining (Sharma et al., 2013). Openness predicts more cooperative behaviors and greater mutual gains in the integrative negotiation (Ma \& Jaeger, 2005; Sharma et al., 2013). In addition, the trait is associated with the tendency to be more flexible and pursue unconventional ideas, which should facilitate integrative agreements (Ma \& Jaeger, 2005).

In addition to the Big Five factors, we aimed to explore if gender influences negotiation planning. Gender differences in negotiation have been studied by numerous scholars (e.g., Bowles et al., 2005; Kray \& Thompson, 2005; Walters et al., 1998). One empirical regularity in this line of research is that male negotiators engage in greater rates of competitive actions and achieve better economic outcomes than female negotiators when bargaining (Mazei et al., 2015). 
Their relevance to negotiation in prior research suggests personality and gender should influence planning behavior. But given the differences between the planning and bargaining phase, and between information evaluation and search, it may be premature to draw inferences based on existing research. Thus, we do not speculate about the exact nature of the relationships between individual differences and preferences and search for information relating to valued outcomes. Instead, an additional focus was to understand when the influence of individual differences could be attenuated, as we explore in the next section.

\section{Situational Constraint and Information Search}

While planning can be conducted as a solitary activity, situational constraints may restrict the expression of personality and gender. Situational strength theory posits that the expression of nonability individual differences can be attenuated when situational factors act as restraints (Meyer \& Dalal, 2009). For example, the level of autonomy afforded to employees and resource constraints can limit how individual differences are expressed in a performative task. In support of this idea, jobs higher in restraint exhibited lower variability in outcomes (Meyer, Dalal, \& Hermida, 2010). Negotiators can face such constraints, as there may be limited time or budget that constrains the length and extent of search, or a lack of information availability may mean extensive search is not possible in the first place. For example, the former president was restrained in the amount of time available to evaluate the 15 boxes of documents during a flight from the US to Singapore. While such considerations may not apply when evaluating among a small number of known options, they can nevertheless affect the search process. It may be possible that greater constraint would lead to attenuated impact of the relationship between personality, gender, and search behavior. 


\section{Overview of Studies}

We conducted four studies to explore how individual differences shape information evaluation and search. Study 1 used a survey design to measure individual differences and to elicit preference for information. In Studies 2, 3, and 4, we deployed a simulation task that measures real search behavior - the Mouselab paradigm (Johnson et al., 1989). The studies varied in the complexity of the search problem, with Studies 2 and 3 featuring a greater number of search elements. Studies 3 and 4 introduced constraints on extent of search allowed. Systematically varying complexity and constraint allowed us to examine the effect of situational constraint on the expression of personality and gender. These studies represented a multi-method approach to studying distinct aspects of the planning phase.

\section{STUDY 1}

In Study 1, we employed a survey method to assess how individuals evaluate and prioritize information related to value claiming, creating, and relationship building. We then examined whether personality and gender predict preference and choice.

\section{METHODS}

\section{Participants}

We recruited participants from Prolific, a crowdsourcing platform for behavioral research. Such platforms provide a means to access high-quality and representative samples (Bohannon, 2016; Crump, McDonnell, \& Gureckis, 2013; Goodman, Cryder, \& Cheema, 2013). Researchers have successfully replicated a wide array of economic and psychological studies using such platforms (Amir, Rand, \& Gal, 2012; Crump et al., 2013; Paolacci, Chandler, \& Ipeirotis, 2010; Suri \& Watts, 2011). Our decision to recruit from Prolific was based on studies 
that demonstrate higher levels of naivety, honesty, and attentiveness of participants compared to Amazon Mechanical Turk (Palan \& Schitter, 2018; Peer, Brandimarte, Samat, \& Acquisti, 2017). 202 participants $(49.5 \%$ female, age $M=32.17, S D=12.38)$ were recruited from Prolific to participate in a 10-minute survey and were compensated with 1.83 USD each. The sample size was selected to have $80 \%$ power to detect a correlation of .20 at a significance level of .05 , calculated using G*Power (Cohen, 1988; Denis, 2019). Data collection involved collecting approximately 30 responses per day.

\section{Procedure}

After providing consent, participants completed a Big Five personality measure. Next, they were briefed about a hypothetical negotiation situation. The situation was based on the Biopharm-Seltek exercise (Greenhalgh, 2001). They assumed the role of a Chief Financial Officer of a company who would negotiate the purchase of a factory to take place in the following week. To prepare for the negotiation, they would direct subordinates to obtain information pertinent to bargaining. The participants completed a short quiz to ensure that they understood the situation and could not progress until they answered all comprehension questions correctly. Then the participants indicated the importance of six kinds of information, two each relating to value claiming, value creating, and relationship. After rating the importance of each piece of information, they made a single choice about which of the six was most important to them. Finally, they provided demographic information.

\section{Measures}

Personality. The 30-item of the Short forms of the Big Five Inventory-2 (BFI-2-S) (Soto $\&$ John, 2017) was used to measure extraversion $(\alpha=.78)$, agreeableness $(\alpha=.77)$ 
conscientiousness $(\alpha=.83)$, neuroticism $(\alpha=.87)$, and openness $(\alpha=.79)$. Participants responded on a 5-point Likert-type scale ( $1=$ Strongly disagree to $5=$ Strongly agree $)$.

Information preference and choice. We developed six items about the negotiation situation that participants could prioritize for their subordinates. Two items related to value claiming ("Information about the most recent market valuation of the land where Startech's plant is located.", "Details about insurance value of the Startech's plant including building and equipment."), two related to value creating ("Information about products and services that Startech should be interested in purchasing from your company.", "Insights into potential collaborative projects with Startech."), and two related to relationships (“Contact details of a former Startech employee, who can advise you on the negotiating style of the Startech CFO.", "Information about industry contacts who can tell you about the Startech CFO's reputation as a negotiator, personality, and his interests in life."). None of the items were labelled with the category they represented. Participants indicated importance on a 7-point Likert-type scale $(1=$ extremely unimportant to $7=$ extremely important). For the three categories of information, we averaged ratings across the two items, given a substantial correlation for all pairs of value claiming $(r=.39, p<.01)$, value creating, $(r=.48, p<.01)$, and relationship information $(r=$ $.46, p<.01)$. After indicating their preference, we listed the six pieces of information again on a new screen. We then asked participants to select a single piece of information that was most important to them.

\section{RESULTS}

We excluded from analyses one participant who failed an attention check and three others who spent less than three minutes on the survey, leaving a final sample of 198 for analysis. Descriptive statistics and correlations are shown in Table 1. Value claiming information was 
given most importance, followed by relationship information, then by value creating information, in terms of both ratings and final choice. Preferences correlated substantially with final choice. There were few associations between individual differences and preference and choice. Agreeableness was positively correlated with preference for relationship information. Neuroticism was negatively related to preference for value creating information. Men choose value claiming information to a greater extent than women.

Insert Table 1 about here

\section{Information Preference}

Personality and gender predicted preferences. We estimated a series of linear regressions with preference for type of information as dependent variables and personality and gender as predictors. Results are shown in Table 2. Conscientiousness, neuroticism, and openness were positively associated with the preference for value claiming information. Neuroticism was negatively associated with preference for value creating information and positively associated with relationship information. Female negotiators preferred value creating information. Agreeableness was positively correlated with preference for relationship information. Extraversion did not predict preference for value creating information, and openness did not predict value creating information.

Insert Table 2 about here 


\section{Choice of Information}

The single choice participants made showed few correlations with individual differences. Table 3 shows the results of multinomial logistic regressions. No coefficient was significant when both personality and gender were entered simultaneously.

Insert Table 3 about here

\section{DISCUSSION}

Personality and gender were associated with preference for different kinds of information. Many of the associations were consistent with findings from what is known about personality. For example, agreeableness predicted a preference for information about relationships. This is consistent with research that shows agreeableness to predict engaging in relationship building activities and generated more psychological value (i.e., justice, fairness, trust, and satisfaction) during the bargaining process (Cable \& Judge, 2003; De Dreu \& Van Lange, 1995). We also observed conscientiousness to predict preference for value claiming information, reflecting tendencies to be achievement striving. Neuroticism predicted preference for information that would help negotiators be more competitive. Some intriguing relationships emerged, including women preferring value creating information. Future studies should replicate and extend these findings to further explain why individual differences lead to preferences for different types of planning information.

Although almost all of the Big Five and gender predicted preferences, individual differences played no role in predicting choice of information. We note that in some cases, personality predicted for a type of information, which in turn predicted a corresponding choice. 
Because we measured those variables in that sequence, we estimated mediation models that examined the link between personality, preferences, and choice on an exploratory basis. We found support for two models, using the Monte Carlo method for mediation (MacKinnon, Lockwood, \& Williams, 2004; Selig \& Preacher, 2008). There was a significant indirect effect of conscientiousness predicting value claiming choice through value claiming preferences (indirect effect $=0.24,95 \% C I=0.03 \sim 0.49)$. We also observed neuroticism predicting value claiming choice through value claiming preferences (indirect effect $=0.19,95 \% C I=0.01 \sim 0.42$ ). In both models, we controlled for remaining Big Five factors and gender. Further exploring such relationships remains a topic for future research.

A limitation of the survey design used in Study 1 is that it only allowed measurement of preferences. The planning process requires more than prioritizing information. In the field, information will rarely present itself in an easy to digest manner. Instead, negotiators must engage in a search process to secure information they will use later on. In Study 2, we aim to address this limitation by simulating a search process for different kinds of information.

\section{STUDY 2}

Personality manifested in preferences for distinct types of information. However, expressing preference for information is distinct from attempts to acquire it. That requires cognitively taxing actions, such as determining what information is relevant, and sorting through alternatives. To simulate the search process, we used the Mouselab paradigm (Johnson et al., 1989). Mouselab aims to capture thinking processes underlying decisions (Payne, Bettman, \& Johnson, 1988, 1993). Mouselab originated from information display boards (IDB), used to measure information search behavior (Payne, 1976). An IDB is a set of index cards arranged in a 
matrix on a noticeboard. The cards hold information regarding a decision the participant asked to make. For example, participants can be asked to consider the purchase of an electric car. Columns of the matrix could represent a particular model of car, and the rows representing categories of information (e.g., price, range, number of seats). Specific information for each model would be written on an index card but facing away from the participant. To reveal any piece of information, they need to turn over the index card, requiring participants to be deliberative in what they seek to know. Before other information is revealed, the revealed card is turned away from the participant. Mouselab is a digital representation of this design, allowing participants to examine virtual panels obscuring information. They can be revealed with the click of a computer mouse (see Figure 1). The program measures which panels were opened, the sequence they were opened in, the time spent on each panel, and decisions made - these comprise objective search behavior. The program offers functions to randomize the order of presentation.

Mouselab has been used across fields of study that share the challenge of measuring search behavior. For example, it demonstrates validity in capturing how consumers make purchase decisions (Mitchell, Kahn, \& Knasko, 1995; Reisen, Hoffrage, \& Mast, 2008), or how people make judgments in strategic interactions like sequential bargaining games (Johnson, Camerer, Sen, \& Rymon, 2002) and two-person guessing games (Costa-Gomes \& Crawford, 2006). Researchers have used the software in the healthcare and law enforcement contexts where information search is completed under the time and budget constraints (Schram \& Sonnemans, 2011; Wastell, Weeks, \& Duncan, 2009). In the field of psychology, Bieleke and colleagues (2020) have recently used Mouselab to study the impact of social value orientation on information acquisition. Mouselab is a versatile approach to investigating information search, 
with results comparable to eye-tracking methods (Bieleke et al., 2020). It has the benefit of being deployable on the internet without specialized equipment.

Insert Figures 1 and 2 about here

In Study 2, we use this paradigm to examine how personality traits and gender predicts search behavior for information related to value creating, claiming, and relationships. We designed the study using an online platform named MouselabWEB (Willemsen \& Johnson, 2008). Our aim in this study was to explore how personality and gender predict search behavior in the absence of constraints.

\section{METHODS}

\section{Participants}

201 participants ( $47.76 \%$ female, age $M=33.61, S D=12.42)$ were recruited from Prolific in exchange for a payment of 2.60 USD. Sample size was determined as per Study 1. We also made the study available for the duration of one week and recruited 28-30 participants per day.

\section{Procedure}

The procedure was similar to Study 1. Participants completed a Big Five personality measure. Then they were briefed about a hypothetical negotiation situation similar to that in Study 1. All features of the negotiation situation were the same, but instead of directing subordinates to gather information, they needed to purchase an information package from one of 
three consulting firms. To ensure they understood the context and instruction given in the above scenario, participants were required to pass a comprehension check. They could not proceed until all answers were correct. Participants were then presented with a three by six information grid (Figure 1). In this grid, information was obscured with an opaque grey panel. Each panel was labelled with the type of information that would be presented. If participants clicked on a panel, information would be revealed to them, and then it reverted to being opaque whey they moved their mouse away. Thus, participants could only examine one panel at a time. Participants had unlimited time and opportunities to view information on the grid and completed a familiarization task on a simplified matrix to ensure comprehension. After making a selection on the information package to purchase, they provided demographic information.

\section{Measures}

Personality. Study 2 used the BFI-2-S (Soto \& John, 2017) as in Study 1. Internal consistencies were acceptable (extraversion $\alpha=.77$, agreeableness $\alpha=.73$, conscientiousness $\alpha$ $=.78$, neuroticism $\alpha=.86$, and openness $\alpha=.81$ ).

Information matrix. In the information matrix, we presented three consulting firms that varied in the information they could provide. The first firm offered two pieces of information regarding value claiming (i.e., value of the land and insurance value of the building). The second firm provided two pieces of value-creating information (i.e., additional opportunities and potential collaborative projects). Finally, the third firm supplied information about relationship building (i.e., behaviors in prior deals and counterpart's personality and interests). These mirrored information provided to participants in Study 1. Full description of the information available is shown in Figure 2. Presentation of the columns and rows was fully randomized. 


\section{RESULTS}

One participant was excluded from the analyses as they provided incomplete responses, leaving a final sample of 200 for analysis. Table 4 reports descriptive statistics and correlations between major variables in the study. On a bivariate level, openness was negatively correlated with the time spent on the task, and the number of clicks on value creating panels. No other correlation reached significance.

Insert Table 4 about here

\section{Patterns in Search Behavior}

We examined aggregate search behavior by tabulating the frequency clicks on each panel. Table 5 shows that clicks were uniformly distributed. We also examined the possibility of participants engaging in one of two heuristic search patterns, namely their first click starting on the top leftmost panel, then moving horizontally to the right, in a direction that mirrors reading. Forty-seven participants (23.5\%) clicked on the top left, middle, and right panels in sequence for their first three clicks. Nine (4.5\%) participants began their search from the top-left panel and moved downward for their first three clicks. Together, a considerable number of participants $(28 \%)$ clicked in a way that suggested a systematic start to the search process.

Insert Table 5 about here

\section{Time Spent Inspecting Panels}


We examined the amount of time participants spent inspecting each type of panel, as well as the overall time spent on the grid. Table 6 displays the regression coefficients that predict the amount of time spent as the dependent variable, and personality and gender as predictors. Agreeableness positively correlated with time spent on inspecting value claiming information, and openness negatively correlated with time inspecting value creating information. Neither personality nor gender predicted time spent on panels about relationships. Agreeableness positively correlated with total time spent on the task while extraversion correlated negatively.

Insert Table 6 about here

\section{Clicks on Type of Information}

We examined the amount of clicks on each type of information panel, as well as the total number of clicks. We initially conducted a series of Poisson regressions as clicks are count data. However, since most of the models were over dispersed, we conducted a series of negative binomial regressions. Table 7 displays odds of clicking on a type of panel. Extraverted negotiators were less likely to click on value claiming panels. Agreeable negotiators were more likely to click on value creating panels, while open negotiators were less likely. Neither personality nor gender predicted clicking on relationship related panels. Agreeable negotiators were more likely to click to a greater extent over all $($ Odds Ratio $(O R)=1.13, p=0.0521)$.

Insert Table 7 about here 


\section{Choice of Dossier}

We next examined the choice participants made following their search. Results of multinomial regressions are shown in Table 8. Openness predicted selecting a dossier emphasizing value claiming information relative to one emphasizing value creating information. Openness predicted lower odds in selecting a dossier emphasizing value creating information to one emphasizing relationships.

Insert Table 8 about here

\section{DISCUSSION}

When there are no constraints on their behavior, negotiators exhibited heuristic search patterns. There was an even distribution of clicks across panels, and many started their search at the top left box and then continued to the right, reflecting a tendency to search in the same direction as they would typically read. This pattern is not necessarily beneficial, since the presentation of panels was fully randomized. This leads us to conclude what negotiators examine first is influenced by layout. There was no evidence that negotiators engaged in prioritized search. We did not observe gender differences.

Personality predicted search behavior in intriguing ways. For instance, despite being frequently associated with integrative bargaining interactions (Barry \& Friedman, 1998; Sharma et al., 2013), openness predicted less time and fewer clicks on value-creating information. However, one consistent pattern was that agreeableness predicted time spent and the number of clicks on panels - it predicts persistence in search. We interpret this to mean that when asked to engage in a relatively complex search task, agreeable people complied with instructions. The 
stark difference in patterns observed across Study 1 and 2 suggest that the way personality expresses itself in planning depends on the nature of the task. Where information can be evaluated without effort, people's personality can correspond with their preferences. When information is obtained through an effortful process, the task may evoke different aspects of personality altogether. This is consistent with the trait activation theory, which proposes that situations and tasks offer differential potential for the expression of a trait (Tett \& Burnett, 2003). For example, openness could predict creative behaviors, but only for tasks that demand a high level of creativity; tasks without such demands may attenuate the relationship between openness and creative output. In a search task, personality did not predict search for or selection of information that aligned with patterns apparent in a preference elicitation task. Instead, we observed expression of a trait associated with compliance.

The patterns observed reflect a situation where no constraints were imposed. Situational strength theory suggests that the influence of individual differences may attenuate when constraints are present (Meyer \& Dalal, 2009). The pattern of relationships observed may be different, or individual differences may not be apparent at all under such conditions.

An alternative possibility that explains the lack of correspondence between personality and search behavior is that it is due to a lack of constraints. The lack of constraints allowed participants to search the matrix in a systematic manner, which many participants ended up doing. In the field, the decision to secure information is costly-for example, time and resources spent enquiring about the insurance value of a factory cannot be redeployed to find out about other kinds of information. Such costs were not represented in the Mouselab paradigm as we deployed it. The cost of examining alternate panels was just a click of a computer mouse, lasting a few seconds. Simulating costs associated with each search attempt may focus negotiators to 
select information they truly value. In the next study, we impose time and click limits to simulate a costly search process. We conducted Study 3 to explore this possibility.

\section{STUDY 3}

We conducted Study 3 to extend Study 2. We deployed the same search paradigm with the same information matrix, but imposed constraints on time allowed and opportunities to interact with the panels. Such constraints may lead negotiators to be more strategic when searching, with the strategic behavior predicted by personality.

\section{METHODS}

\section{Participants}

We recruited 300 participants ( $43.33 \%$ female, age $M=31.48, S D=11.74)$ from Prolific and compensated each of them with 2.60 USD. As per previous studies, the minimum sample size was calculated using G*Power method (Cohen, 1988; Denis, 2019). We recruited 41-43 participants per day.

\section{Procedure}

The procedure was nearly identical to Study 2. Participants first completed a Big Five personality measure. Next, they were briefed about the same hypothetical negotiation scenario and exposed to the same information matrix as described in Study 2. However, they were informed that they could only click on up to six panels and have a maximum of five minutes for the search process. The timer started when they clicked on the first panel. Once they clicked on six panels or reached the time limit, they were not allowed to examine any additional panels. As in Study 2, participants needed to pass a comprehension check and complete a familiarization 
task before interacting with the information matrix. After selecting the information package to purchase, they provided demographic information.

\section{Measures}

Personality. Study 3 also used the BFI-2-S (Soto \& John, 2017), as in Studies 1 and 2. Internal consistencies were acceptable (extraversion $\alpha=.74$, agreeableness $\alpha=.75$, conscientiousness $\alpha=.82$, neuroticism $\alpha=.85$, and openness $\alpha=.81$ ).

Information matrix. The information matrix used in Study 3 was identical to the one used in Study 2.

\section{RESULTS}

Two participants were omitted from the analyses due to incomplete responses. Excluding these cases left a final sample of 298. Table 9 provides descriptive statistics and correlations between variables measured. We observed a negative correlation between neuroticism and the total time spent on the task. All other correlations were not significant.

Insert Table 9 about here

\section{Patterns in Search Behavior}

We tabulated the aggregated frequency of visits for each panel, as shown on Table 10. There was an unequal distribution of clicks. The majority of clicks concentrated on one piece of information within each category. As in Study 2, we also inspected the prevalence of two heuristic search patterns, including clicking on the panels from the left moving right for the first 
row and from the top left moving downward for the first column. While eighteen participants $(6.04 \%)$ engaged in the former heuristic search pattern, none of them $(0 \%)$ involved in the latter one. Only a small portion of participants began their search in a systematic manner. Participants engaged in more strategic search behavior when confronted with constraints.

Insert Table 10 about here

\section{Time Spent Inspecting Panels}

We employed a series of linear regression analyses to analyze the amount of time participants devoted to examining each type of panel and the entire information grid. The standardized regression coefficients were reported in Table 11. Openness was negatively associated with time spent on studying value creating information. Neuroticism was negatively associated with the total time inspecting the entire grid. No other significant associations were found.

Insert Table 11 about here

\section{Clicks on Type of Information}

We only examined the frequency of clicks on each type of information as there was little variability in the total number of clicks $(M=5.87, S D=0.53)$. Since the data on the dependent variables were mostly over dispersed, we estimated a series of negative binomial regressions. 
Table 12 displays the results. Neither personality nor gender significantly predicted the number of clicks on any type of information panel.

Insert Table 12 about here

\section{Choice of Dossier}

As in Study 2, we also conducted a series of multinomial logistic regressions to examine choice of dossier. Table 13 displays the results. Openness was associated with choosing the relationship focused dossier over the value creating dossier. No other individual differences predicted choice of dossier.

Insert Table 13 about here

\section{DISCUSSION}

When time and click limits were imposed, we only observed three associations. Openness negatively correlated with time spent on value creating boxes and predicted selection of relationship over value creating choice. Neuroticism negatively correlated with the overall time spent on panels. The reduction in the number of associations between personality and search behavior is consistent with situational strength theory (Meyer \& Dalal, 2009). The theory proposes that constraints on behavior attenuates the expression of personality, which we observe in contrast to Study 2. In addition, agreeableness, a predictor of persistent search in Study 2, was not apparent in this study, given the limits imposed. 
However, we also observed that constraint resulted in more strategic information search, but this was not apparent in how personality predicted measures of search duration, clicks, nor choice of information. The strategic nature of the search reflected a tendency to sample different types of information; trends reflected a tendency to know something about each category of information, but not about everything about a given category.

We aimed to explore the impact of one additional situational constraint, namely task complexity. In Study 3, we observed participants to engage strategically with the matrix of panels, and constraints imposed meant that there was a high amount of uncertainty about information in the panels that could be inspected. Greater uncertainty could have contributed to the attenuation of the relationship between individual differences and search behavior, independent of constraint. We explore this possibility in Study 4 by reducing the complexity of the task.

\section{STUDY 4}

Study 4 served to extended Study 3 by examining the impact of reduced complexity in the information matrix while imposing the same restrictions on the time and number of clicks. Study 4 should further clarify the role of constraint and complexity in the relationship between personality and information search.

\section{METHODS}

\section{Participants}

325 participants (46.77\% female, age $M=34.66, S D=13.35)$ were recruited from Prolific in exchange for 2.60 USD in compensation. Similar to previous studies, the sample size was predetermined using G*Power (Cohen, 1988; Denis, 2019). We recruited 41-43 participants per day. 


\section{Procedure}

The procedure was identical to Study 3.

\section{Measures}

Personality. As in previous studies, we also used the BFI-2-S (Soto \& John, 2017) to assess the participants' personality traits. Internal consistencies were acceptable (extraversion $\alpha$ $=.80$, agreeableness $\alpha=.79$, conscientiousness $\alpha=.82$, neuroticism $\alpha=.88$, and openness $\alpha=$ .77).

Information matrix. The information matrix used in Study 4 was a simplified version of the matrix used in Studies 2 and 3. Participants were exposed to a three-by-three instead of a three-by-six matrix (Figure 3). The simplification involved having just one aspect of value creating, or value claiming, or relationship building information for each dossier. As in Study 3, participants could click on up to six panels and had a maximum of five minutes to complete the task.

\section{RESULTS}

Due to a filtering error, 29 participants using smartphones and tablets were allowed to participate in Study 4. As MouselabWEB is not fully compatible with these devices, we decided to omit their responses. We also excluded another eight participants from the analyses, including five people who provided incomplete responses, two people who reported technical difficulties, and one person who provided personality data with zero variance (i.e., straight-lining response; Kim, Dykema, Stevenson, Black, \& Moberg, 2019). We were left with a final sample of 288 after dropping these cases. Descriptive statistics and correlations between major variables are 
shown in Table 14. Neuroticism was negatively associated with the number of clicks on value claiming panels. We detected no other significant correlations.

Insert Table 14 about here

\section{Patterns in Search Behavior}

To explore patterns in search behavior, we examined the aggregated frequency of visits for each panel. Table 15 shows that clicks were distributed relatively evenly. Some evidence of a heuristic pattern emerged. Sixty-four (22\%) participants started their search from the top left panel and moved to the right for their first three clicks. Only six (2\%) participants began their search from the same position and moved downward for their first three clicks. Overall, a significant portion of participants demonstrated systematic search behavior.

Insert Table 15 about here

\section{Time Spent Inspecting Panels}

Individual differences did not predict time spent inspecting panels. We conducted a series of linear regressions to predict the amount of time participants spent on each type of panel and the total time they spent on the grid. Table 16 presents the results. Neither personality nor gender predicted time spent on any type of panel nor total time spent. 
Insert Table 16 about here

\section{Clicks on Type of Information}

As in Study 3, there was little variability in total clicks $(M=5.95, S D=0.22)$. Thus, we only examined clicks on each type of information panel. We conducted a series of Poisson regressions because overdispersion was not observed. Table 17 presents the results. Personality and gender did not predict frequency of clicks for any type of panel.

Insert Table 17 about here

\section{Choice of Dossier}

Individual differences did not predict dossier choice. We also carried out a series of multinomial logistic regressions to predict choice, with the results displayed in Table 18. Neither personality nor gender predicted the final choice of dossier.

Insert Table 18 about here

\section{DISCUSSION}

In a simplified information matrix of panels where most could be examined, negotiators appeared less deliberate in their behavior. About a quarter relied on heuristic approaches to complete the task. This is similar to the pattern observed in Study 2 . 
Simplification of the task did not lead to personality or gender predicting search behavior. This is consistent with situational strength theory, which suggests that constraint attenuates the expression of individual differences. Individual differences did not predict behavior in a simple and constrained task.

\section{GENERAL DISCUSSION}

Our research offers the first insights into how people plan to negotiate. In particular, we provide an initial understanding of the role personality and gender have in the planning process. We outline four major discoveries about the planning process.

First, personality and gender can predict what information people deem as being important. Although the role of personality in negotiation has been questioned (Elfenbein, 2015) and observed effect sizes between personality and negotiation outcomes in simulations have been small (Sharma et al., 2013), they can play a substantial role in shaping how people think about and search for information that contributes to negotiation outcomes. When people evaluate information related to negotiations, Study 1 shows preferences can be predicted by personality. However, consistency between personality and preference did not translate to search behavior. In Study 2, agreeableness predicted persistence in a search task, which we attribute to agreeable people being compliant. Research shows that agreeableness is associated compliant behaviors such as lower rates of disobedience among children and lower arrest rates among adults (Laursen, Pulkkinen, \& Adams, 2002), and greater rate of volunteering (Carlo, Okun, Knight, \& de Guzman, 2005). This pattern was not observed in Studies 3 and 4, where constraints were placed on search. This suggests that behavior in distinct kinds of planning tasks elicit a different pattern of relationships with personality. Where the task requires little effort, personality appears to predict preferences. However, when the task is complex and requires effort, factors that 
predict behavior are those related to compliance. Both task type and task complexity appear to be a factor in how individual differences predict behavioral patterns, consistent with both situational strength theory (Meyer \& Dalal, 2009) and trait activation theory (Tett \& Burnett, 2003). As negotiators are free to determine the amount of information they choose to evaluate or the complexity of the search process, the expression of individual differences could depend on initial choices they make about the process or situational constraints that moderate information availability.

This discovery has several implications. Researchers wishing to understand negotiation situations should theorize about both individual differences and situational factors that contribute to behavior, consistent with the interactionist perspective which posits that both person and situational factors contribute to observed attitudes, cognitions, and behaviors (Terborg, 1981). This means that null effects of personality, as observed in Study 4, can still be informative. In context of the two other studies that demonstrated significant relationships, the null effects provide information about the amount of situational constraint necessary to eliminate observed individual differences. Thus, positing individual differences where constraint is high, or not theorizing their presence when constraint is low may lead to mis-specified models. There may be many cases where individual differences predict attitudes, cognitions, and behavior across the negotiation process.

Second, we observed remarkably few gender differences across studies. Only one significant difference emerged, with women having greater preference for value creating information. There were no differences in objective search behavior across multiple dimensions and multiple studies. Although a replicated finding shows that women claim less value than men 
(Mazei et al., 2015). Our findings suggest that such disparities in outcomes are not likely to be a result of differences in planning efforts.

Third, the search process is subject to heuristics. Negotiators initiated search in a manner following common reading pattern in Studies 2 and 4, when all or most of the matrix could be examined. In Study 3, participants selectively sampled information when much of the matrix could not be examined. This shows that search heuristics depend on the form of constraint. Strategic search was deployed when there is no possibility of examining all of the information. When most or all of the information can be examined, many people figuratively and literally 'start from the top'. Better understanding how and why these heuristics are deployed will facilitate knowledge about how people search for information. Descriptive statistics also revealed striking patterns. In the survey design of Study 1, the majority (56\%) of negotiators chose value claiming information as the most important, but a considerable number (26\%) chose relationship information as being the most important. Only about a fifth (18\%) chose value creating information - despite the implication it has for value claiming. In studies involving the Mouselab paradigm, the consistently most chosen dossier was the one containing information about relationships (Study 2: 40\%, Study 3: 36\%, Study 4: 45\%). Although we cannot identify why the difference arises, one possibility is that the characteristics of the task may lead to systematic biases.

Fourth, personality plays a significant role in information evaluation. What negotiators deem to be important varies as a function of the Big Five factors. This implies that personality can predict what issues are valued, with downstream consequences for the formulation of arguments, what is said during bargaining, the terms that are represented in agreements, and ultimately, what is implemented. Much negotiation research to date has relied on bargaining 
study designs that exogenously impose what people should value (Jang et al., 2018). In contrast, this research begins to explore how individual differences can be informative about a negotiator's utility function. Future research should adopt designs that allow negotiators to express how they value issues and study their relationship with individual differences (e.g., Greenhalgh, Neslin, \& Gilkey, 1985).

\section{Limitations and Future Research}

We note multiple avenues for future research. First, we consider factors related to the limitations of the studies then take a step back to consider other possibilities not addressed in this paper.

The search process modeled by the Mouselab paradigm is highly stylized. It presumes that all of the options are known, that every aspect of the situation is knowable, and that search comprises searching among known options. But in the field, negotiators likely will need to define the options as well as the attributes before engaging in the task simulated by Mouselab. Information search can also be an interactive process, which involves people approaching others, such as requesting an interview with a former employee of a target company, rather than purchasing or searching for information in a digital format. Search is more than inspecting a matrix, and much future research awaits to fully explore the topic of how negotiators search for information.

We also note that individual differences generally did not predict choice of information. Although few significant bivariate relationships and post hoc mediations were observed, the Big Five and gender rarely predicted what information people ultimately chose. Moreover, when some significant relationships were observed, they were counterintuitive. For example, in Study 2, open negotiators were less likely to click on value creating panels, and in Study 3, they were 
likely to choose a relationship focused dossier over a value creating one. Future research could replicate and extend these observations to achieve better understanding of such relationships. We next consider factors not examined in the current research as avenues for future exploration about the planning phase.

Planning can be conducted alone, but it can also be the result of an interactive process. Negotiation can arise from disputes, necessitating discussion about the limits of the issues to be discussed before bargaining occurs (Gulliver, 1979; Williams, 1985), or the process may involve intra-organizational bargaining before the focal negotiation (Walton \& McKersie, 1965). Moreover, in particularly creative negotiation behavior can involve extensive social interactions. For example, negotiators for Kennecott Copper faced their mine being nationalized. Their planning involved a highly creative and active process that involved contacting prospective buyers for ore, seeking guarantors for loans and having them subject to a foreign power, and selling collection rights to banks in a different set of countries (Lax \& Sebenius, 2006). Such aspects of planning deserve greater research focus.

Information is varied and not always relevant. Complex negotiations require consideration of many pieces of information, and their value is not always apparent, nor linked to valued outcomes. In the field, negotiators can potentially evaluate and search vast amounts of information. For example, free trade agreements may comprise hundreds of pages of terms and conditions. Insight into what people find relevant and what they attempt to use to further their goals is an avenue for better understanding how negotiators think about the planning process.

Although we adopted an individual differences perspective in investigating planning, there are other ways to explore planning phenomena. For example, cross-cultural differences may influence how negotiators approach planning. Other factors may include organizational 
policies and norms influence how negotiators approach the planning phase. Examining such factors, either on their own or in concert with individual differences factors should furnish the literature with greater insights about the complexity of the negotiation process.

Finally, evaluating and searching for information are only a part of planning. As Peterson and Lucas (2001) pointed out, information evaluation and search is only a part of intelligence gathering. There are other aspects of planning, including formulating bargaining objectives, developing a strategy, as well as rehearsing for the bargaining phase. Those aspects of planning await empirical exploration. 


\section{REFERENCES}

Adair, W. L., \& Brett, J. M. 2005. The negotiation dance: Time, culture, and behavioral sequences in negotiation. Organization Science, 16(1): 33-51.

Ajzen, I. 1991. The theory of planned behavior. Organizational Behavior and Human Decision Processes, 50(2): 179-211.

Alexander, J. F., Schul, P. L., \& McCorkle, D. E. 1994. An assessment of selected relationships in a model of the industrial marketing negotiation process. The Journal of Personal Selling \& Sales Management, 14(3): 25-41.

Allen, J., \& Clark, D. (2018, June 8). Trump: “I don’t think I have to prepare very much” for nuclear summit. NBC News. Accessed online at https://www.nbcnews.com/politics/white-house/trump-i-don-t-think-i-have-prepare-verymuch-n880981. Viewed 11 August, 2021.

American Bar Association. 2009. American Bar Association guide to resolving legal disputes: Inside and outside the courtroom. New York, NY: Random House Reference.

Amir, O., Rand, D. G., \& Gal, Y. K. 2012. Economic games on the internet: The effect of \$1 stakes. PLoS ONE, 7(2): e31461.

Aronoff, J., \& Wilson, J. P. 2014. Personality in the social process. New York, NY: Psychology Press.

Bardos, A. N., Naglieri, J. A., \& Prewett, P. N. 1992. Gender differences on planning, attention, simultaneous, and successive cognitive processing tasks. Journal of School Psychology, 30(3): 293-305.

Barley, S. R. 1991. Contextualizing conflict: Notes on the anthropology of disputes and negotiations. In M. H. Bazerman, R. J. Lewicki \& B. H. Sheppard (Eds.), Handbook of 
negotiation research, vol. 3 Research on negotiation in organizations: 165-199. Greenwich CT: JAI Press.

Barrick, M. R., \& Mount, M. K. 1991. The Big Five personality dimensions and job performance: A meta-analysis. Personnel Psychology, 44(1): 1-26.

Barry, B., \& Friedman, R. A. 1998. Bargainer characteristics in distributive and integrative negotiation. Journal of Personality and Social Psychology, 74(2): 345-359.

Bieleke, M., Dohmen, D., \& Gollwitzer, P. M. 2020. Effects of social value orientation (SVO) and decision mode on controlled information acquisition-A Mouselab perspective. Journal of Experimental Social Psychology, 86: 103896.

Bitterly, T. B., \& Schweitzer, M. E. 2020. The economic and interpersonal consequences of deflecting direct questions. Journal of Personality and Social Psychology, 118(5): 945990.

Bohannon, J. 2016. Mechanical Turk upends social sciences. Science, 352(6291): 1263-1264.

Bowles, H. R., Babcock, L., \& McGinn, K. L. 2005. Constraints and triggers: Situational mechanics of gender in negotiation. Journal of Personality and Social Psychology, 89(6): 951-965.

Cable, D. M., \& Judge, T. A. 2003. Managers' upward influence tactic strategies: The role of manager personality and supervisor leadership style. Journal of Organizational Behavior, 24(2): 197-214.

Carlo, G., Okun, M. A., Knight, G. P., \& de Guzman, M. R. T. 2005. The interplay of traits and motives on volunteering: Agreeableness, extraversion and prosocial value motivation. Personality and Individual Differences, 38(6): 1293-1305. 
Carnevale, P. J., \& De Dreu, C. K. W. 2006. Motive: The negotiator's raison d'e^tre. In L. L. Thompson (Ed), Negotiation theory and research: 55-76. New York, NY: Psychology Press.

Cohen, J. 1988. Statistical power analysis for the behavioral sciences (2nd ed). Hillsdale, N.J:

L. Erlbaum Associates.

Costa, P. T., \& McCrae, R. R. 1992a. Revised NEO personality inventory (NEO PI-R) and NEP five-factor inventory (NEO-FFI): Professional manual. Odessa, FL:

Psychological Assessment Resources.

Costa, P. T., \& McCrae, R. R. 1992b. Four ways five factors are basic. Personality and Individual Differences, 13(6): 653-665.

Costa-Gomes, M. A., \& Crawford, V. P. 2006. Cognition and behavior in two-person guessing games: An experimental study. The American Economic Review, 96(5): 32.

Crump, M. J. C., McDonnell, J. V., \& Gureckis, T. M. 2013. Evaluating Amazon's Mechanical Turk as a tool for experimental behavioral research. PLOS ONE, 8(3): e57410.

Curhan, J. R., Elfenbein, H. A., \& Kilduff, G. J. 2009. Getting off on the right foot: Subjective value versus economic value in predicting longitudinal job outcomes from job offer negotiations. Journal of Applied Psychology, 94(2): 524-534.

Curhan, J. R., Elfenbein, H. A., \& Xu, H. 2006. What do people value when they negotiate? Mapping the domain of subjective value in negotiation. Journal of Personality and Social Psychology, 91(3): 493-512.

De Dreu, C. K. W., \& Van Lange, P. A. M. 1995. The impact of social value orientations on negotiator cognition and behavior. Personality and Social Psychology Bulletin, 21(11): $1178-1188$. 
Denis, D. J. 2019. SPSS data analysis for univariate, bivariate, and multivariate statistics. Hoboken, NJ: John Wiley, Inc.

Dimotakis, N., Conlon, D. E., \& Ilies, R. 2012. The mind and heart (literally) of the negotiator: Personality and contextual determinants of experiential reactions and economic outcomes in negotiation. Journal of Applied Psychology, 97(1): 183-193.

Elfenbein, H. A. 2015. Individual differences in negotiation: A nearly abandoned pursuit revived. Current Directions in Psychological Science, 24(2): 131-136.

Feist, G. J. 1998. A meta-analysis of personality in scientific and artistic creativity. Personality and Social Psychology Review, 2(4): 290-309.

Fisher, R., Ury, W., \& Patton, B. 2011. Getting to yes: Negotiating agreement without giving in. New York, NY: Penguin.

Gelfand, M. J., Major, V. S., Raver, J. L., Nishii, L. H., \& O’Brien, K. 2006. Negotiating relationally: The dynamics of the relational self in negotiations. Academy of Management Review, 31(2): 427-451.

Gensowski, M. 2018. Personality, IQ, and lifetime earnings. Labour Economics, 51: 170-183.

Glass, J. C., \& Kilpatrick, B. B. 1998. Financial planning for retirement: An imperative for baby boomer women. Educational Gerontology, 24(6): 595-617.

Goodman, J. K., Cryder, C. E., \& Cheema, A. 2013. Data collection in a flat world: The strengths and weaknesses of mechanical Turk samples. Journal of Behavioral Decision Making, 26(3): 213-224.

Gray, B. 1989. Collaborating: Finding common ground for multiparty problems. San Francisco, CA: Jossey-Bass. 
Graziano, W. G., Jensen-Campbell, L. A., \& Hair, E. C. 1996. Perceiving interpersonal conflict and reacting to it: The case for agreeableness. Journal of Personality and Social Psychology, 70(4): 820-835.

Greenhalgh, L. 2001. The Biopharm-Seltek negotiation. Dispute Resolution Research Center.

Greenhalgh, L., \& Chapman, D. I. 1998. Negotiator relationships: Construct measurement, and demonstration of their impact on the process and outcomes of negotiation. Group Decision and Negotiation, 7(6): 465-489.

Greenhalgh, L., Neslin, S. A., \& Gilkey, R. W. 1985. The effects of negotiator preferences, situational power, and negotiator personality on outcomes of business negotiations. The Academy of Management Journal, 28(1): 9-33.

Gulliver, P. H. 1979. Disputes \& negotiations: A cross-cultural perspective. New York, NY, US: Academic Press.

Hayes-Roth, B., \& Hayes-Roth, F. 1979. A cognitive model of planning. Cognitive Science, 3(4): 275-310.

Hilty, J. A., \& Carnevale, P. J. 1993. Black-hat/white-hat strategy in bilateral negotiation. Organizational Behavior and Human Decision Processes, 55(3): 444-469.

Jacobs-Lawson, J. M., Hershey, D. A., \& Neukam, K. A. 2004. Gender differences in factors that influence time spent planning for retirement. Journal of Women \& Aging, 16(3-4): 5569.

Jang, D., Elfenbein, H. A., \& Bottom, W. P. 2018. More than a phase: Form and features of a general theory of negotiation. Academy of Management Annals, 12(1): 318-356. 
John, O. P., \& Srivastava, S. 1999. The big five trait taxonomy: History, measurement, and theoretical perspectives. In O. P. John, R. W. Robins \& L. A. Pervin (Eds), Handbook of personality: Theory and research: 102-138. New York, NY, US: Guilford Press.

Johnson, E. (2018, June 7). Trump and Bolton spurn top-level North Korea planning. Politico. Accessed online at https://politi.co/2sMwQZD. Viewed 11 August, 2021.

Johnson, E. J., Camerer, C., Sen, S., \& Rymon, T. 2002. Detecting failures of backward induction: Monitoring information search in sequential bargaining. Journal of Economic Theory, 104(1): 16-47.

Johnson, E. J., Payne, J. W., Bettman, J. R., \& Schkade, D. A. 1989. Monitoring information processing and decisions: The mouselab system. DTIC Document. http://oai.dtic.mil/oai/oai?verb=getRecord\&metadataPrefix=html\&identifier=ADA20596 3.

Keeney, R. L., \& Raiffa, H. 1991. Structuring and analyzing values for multiple-issue negotiations. In H. P. Young (Ed.), Negotiation analysis: 131-151. Ann Arbor, MI, US: University of Michigan Press.

Kennan, G. F., \& Mearsheimer, J. J. 2012. American diplomacy (60th-anniversary expanded edition ed.). Chicago, IL: University of Chicago Press.

Kerr, S. 1975. On the folly of rewarding A, while hoping for B. Academy of Management Journal, 18(4): 769-783.

Kim, Y., Dykema, J., Stevenson, J., Black, P., \& Moberg, D. P. 2019. Straightlining: Overview of measurement, comparison of indicators, and effects in mail-web mixed-mode surveys. Social Science Computer Review, 37(2): 214-233. 
Kray, L. J., \& Thompson, L. 2005. Gender stereotypes and negotiation performance: An examination of theory and research. Research in Organizational Behavior, 26: 103-182.

Laursen, B., Pulkkinen, L., \& Adams, R. 2002. The antecedents and correlates of agreeableness in adulthood. Developmental Psychology, 38(4): 591-603.

Lax, D. A., \& Sebenius, J. K. 2006. 3-D negotiation: Powerful tools to change the game in your most important deals. Boston, MA, US: Harvard Business Press.

Letkiewicz, J. C., \& Fox, J. J. 2014. Conscientiousness, financial literacy, and asset accumulation of young adults. Journal of Consumer Affairs, 48(2): 274-300.

Lewicki, R. J., \& Litterer, J. A. 1985. Negotiation. Homewood, IL, US: McGraw-Hill.

Ma, Z., \& Jaeger, A. 2005. Getting to yes in China: Exploring personality effects in Chinese negotiation styles. Group Decision and Negotiation, 14(5): 415-437.

MacKinnon, D. P., Lockwood, C. M., \& Williams, J. 2004. Confidence limits for the indirect effect: Distribution of the product and resampling methods. Multivariate Behavioral Research, 39(1): 99-128.

Mayer, K. J., \& Argyres, N. S. 2004. Learning to contract: Evidence from the personal computer industry. Organization Science, 15(4): 394-410.

Mazei, J., Hüffmeier, J., Freund, P. A., Stuhlmacher, A. F., Bilke, L., et al. 2015. A metaanalysis on gender differences in negotiation outcomes and their moderators. Psychological Bulletin, 141(1): 85-104.

McCrae, R. R., \& John, O. P. 1992. An introduction to the five-factor model and its applications. Journal of Personality, 60(2): 175-215. 
McKelvey, T. (2018, June 9). Trump-Kim talks: How well has Trump prepared for Singapore? BBC News. Accessed online at https://www.bbc.com/news/world-us-canada-44421454. Viewed 11 August, 2021.

McMains, M. J., \& Mullins, W. C. 2013. Crisis negotiations: Managing critical incidents and hostage situations in law enforcement and corrections (5th ed.). New York, NY: Routledge.

Meyer, R. D., \& Dalal, R. S. 2009. Situational strength as a means of conceptualizing context. Industrial and Organizational Psychology, 2(1): 99-102.

Meyer, R. D., Dalal, R. S., \& Hermida, R. 2010. A review and synthesis of situational strength in the organizational sciences. Journal of Management, 36(1): 121-140.

Mislin, A. A., Boumgarden, P. A., Jang, D., \& Bottom, W. P. 2015. Accounting for reciprocity in negotiation and social exchange. Judgment and Decision Making, 10(6): 571-589.

Mitchell, D. J., Kahn, B. E., \& Knasko, S. C. 1995. There's something in the air: Effects of congruent or incongruent ambient odor on consumer decision making. Journal of Consumer Research, 22(2): 229-238.

Moore, D. A. 2004. The unexpected benefits of final deadlines in negotiation. Journal of Experimental Social Psychology, 40(1): 121-127.

Mount, M. K., Barrick, M. R., \& Stewart, G. L. 1998. Five-factor model of personality and performance in jobs involving interpersonal interactions. Human Performance, 11(2/3): $145-165$.

Naglieri, J. A., \& Rojahn, J. 2001. Gender differences in planning, attention, simultaneous, and successive (PASS) cognitive processes and achievement. Journal of Educational Psychology, 93(2): 430-437. 
Odell, J. S. 2000. Negotiating the World Economy ( $1^{\text {st }}$ ed.). Ithaca, NY: Cornell University Press.

Palan, S., \& Schitter, C. 2018. Prolific.ac-A subject pool for online experiments. Journal of Behavioral and Experimental Finance, 17: 22-27.

Paolacci, G., Chandler, J., \& Ipeirotis, P. G. 2010. Running experiments on Amazon Mechanical Turk. Judgment and Decision Making, 5(5): 411-419.

Payne, J. W. 1976. Task complexity and contingent processing in decision making: An information search and protocol analysis. Organizational Behavior and Human Performance, 16(2): 366-387.

Payne, J. W., Bettman, J. R., \& Johnson, E. J. 1988. Adaptive strategy selection in decision making. Journal of Experimental Psychology: Learning, Memory, and Cognition, 14(3): 534-552.

Payne, J. W., Bettman, J. R., \& Johnson, E. J. 1993. The adaptive decision maker. Cambridge: Cambridge University Press.

Peer, E., Brandimarte, L., Samat, S., \& Acquisti, A. 2017. Beyond the Turk: Alternative platforms for crowdsourcing behavioral research. Journal of Experimental Social Psychology, 70: 153-163.

Peterson, R. M., \& Lucas, G. H. 2001. Expanding the antecedent component of the traditional business negotiation model: Pre-negotiation literature review and planning-preparation propositions. Journal of Marketing Theory and Practice, 9(4): 37-49.

Pinkley, R. L., Conlon, D. E., Sawyer, J. E., Sleesman, D. J., Vandewalle, D., et al. 2019. The power of phantom alternatives in negotiation: How what could be haunts what is.

Organizational Behavior and Human Decision Processes, 151: 34-48. 
Pruitt, D. G., \& Carnevale, P. J. 1993. Negotiation in social conflict. Belmont, CA, US: Brooks/Cole Publishing Company.

Quick, H. E., \& Moen, P. 1998. Gender, employment and retirement quality: A life course approach to the differential experiences of men and women. Journal of Occupational Health Psychology, 3(1): 44-64.

Quinn, J. B. 1980. Strategies for change: Logical incrementalism. Homewood, IL: R.D. Irwin. Rackham, N. 1988. Spin selling (1st ed.). New York, NY: McGraw-Hill.

Raiffa, H. 1982. The art and science of negotiation. Cambridge, MA, US: Harvard University Press.

Reisen, N., Hoffrage, U., \& Mast, F. W. 2008. Identifying decision strategies in a consumer choice situation. Judgment and Decision Making, 3(8): 641-658.

Rogers, M. E., Creed, P. A., \& Glendon, A. I. 2008. The role of personality in adolescent career planning and exploration: A social cognitive perspective. Journal of Vocational Behavior, 73(1): 132-142.

Roloff, M. E., Putnam, L. L., \& Anastasiou, L. 2003. Negotiation skills. In J. O. Greene \& B. R. Burleson (Eds), Handbook of communication and social interaction skills: 801-833. Mahwah, NJ, US: Lawrence Erlbaum Associates Publishers.

Sanger, D. E., \& Wong, E. (2019, March 2). How the Trump-Kim summit failed: Big threats, big egos, bad bets. The New York Times. Accessed online at https://www.nytimes.com/2019/03/02/world/asia/trump-kim-jong-un-summit.html. Viewed 11 August, 2021.

Schneider, A. K., \& Honeyman, C. 2006. The Negotiator's Fieldbook. Washington, DC: American Bar Association. 
Schram, A., \& Sonnemans, J. 2011. How individuals choose health insurance: An experimental analysis. European Economic Review, 55(6): 799-819.

Schultz, N. O., Collins, A. B., \& McCulloch, M. 1994. The ethics of business intelligence. Journal of Business Ethics, 13(4): 305-314.

Selig, J. P., \& Preacher, K. J. 2008. Monte Carlo method for assessing mediation: An interactive tool for creating confidence intervals for indirect effects. Accessed online at http://quantpsy.org/medmc/medmc111.htm. Viewed Jun 17, 2021.

Sharma, S., Bottom, W. P., \& Elfenbein, H. A. 2013. On the role of personality, cognitive ability, and emotional intelligence in predicting negotiation outcomes: A meta-analysis. Organizational Psychology Review, 3(4): 293-336.

Simmons, B. A., \& Betschild, M. J. 2001. Women's retirement, work and life paths: Changes, disruptions and discontinuities. Journal of Women \& Aging, 13(4): 53-70.

Sorensen, S., Duberstein, P. R., Chapman, B., Lyness, J. M., \& Pinquart, M. 2008. How are personality traits related to preparation for future care needs in older adults? The Journals of Gerontology: Psychological Sciences, 63(6): P328-P336.

Soto, C. J., \& John, O. P. 2017. Short and extra-short forms of the big five inventory-2: The BFI-2-S and BFI-2-XS. Journal of Research in Personality, 68: 69-81.

Stuhlmacher, A. F., \& Adair, C. K. 2011. Personality and negotiation. In M. Benoliel (Ed.), Negotiation excellence—Successful deal making: 195-210. Singapore: World Scientific Publishing.

Suri, S., \& Watts, D. J. 2011. Cooperation and contagion in web-based, networked public goods experiments. ACM SIGecom Exchanges, 10(2): 3-8. 
Tedeschi, J., Burrill, D., \& Gahagan, J. 1969. Social desirability, manifest anxiety, and social power. The Journal of Social Psychology, 77(2): 231-239.

Terborg, J. R. 1981. Interactional psychology and research on human behavior in organizations. Academy of Management Review, 6(4): 569-576.

Tett, R. P., \& Burnett, D. D. 2003. A personality trait-based interactionist model of job performance. Journal of Applied Psychology, 88(3): 500-517.

Thompson, L., \& Hastie, R. 1990. Social perception in negotiation. Organizational Behavior and Human Decision Processes, 47(1): 98-123.

Tibergien, M. C., \& Dahl, O. 2006. How to value, buy, or sell a financial advisory practice: A manual on mergers, acquisitions, and transition planning. Hoboken, NJ: Bloomberg Press.

Tinsley, C. H., O’Connor, K. M., \& Sullivan, B. A. 2002. Tough guys finish last: The perils of a distributive reputation. Organizational Behavior and Human Decision Processes, 88(2): 621-642.

Toosi, N. (2018, May 31). Trump team doesn't know what it wants from North Korea. Politico. Accessed online at https://politi.co/2J0Q08W. Viewed 11 August, 2021.

Walters, A. E., Stuhlmacher, A. F., \& Meyer, L. L. 1998. Gender and negotiator competitiveness: A meta-analysis. Organizational Behavior and Human Decision Processes, 76(1): 1-29.

Walton, R. E., \& McKersie, R. B. 1965. A behavioral theory of labor negotiations: An analysis of a social interaction system. New York, NY: McGraw-Hill.

Walton, R. E., \& McKersie, R. B. 1991. A behavioral theory of labor negotiations: An analysis of a social interaction system. Ithaca, N.Y: Cornell University Press. 
Warrick, P. D., \& Naglieri, J. A. 1993. Gender differences in planning, attention, simultaneous, and successive (PASS) cognitive processes. Journal of Educational Psychology, 85(4): $693-701$.

Wastell, C. A., Weeks, N., \& Duncan, P. 2009. Sintella: Simulation of intelligence analysis. Journal of Policing, Intelligence and Counter Terrorism, 4(2): 71-81.

White, J. B., Tynan, R., Galinsky, A. D., \& Thompson, L. 2004. Face threat sensitivity in negotiation: Roadblock to agreement and joint gain. Organizational Behavior and Human Decision Processes, 94(2): 102-124.

Willemsen, M. C., \& Johnson, E. J. 2008. MouselabWEB. http://www.mouselabweb.org/designer/.

Williams, G. R. 1985. A lawyer's handbook for effective negotiation and settlement. Seattle, WA: Washington State Bar Association.

Zartman, I. W. 2006. Process and stages. In A. K. Schneider \& C. Honeyman (Eds.), The negotiator's fieldbook: The desk reference for the experienced negotiator: 95-98. Washington, DC, US: American Bar Association.

Zetik, D. C., \& Stuhlmacher, A. F. 2002. Goal setting and negotiation performance: A metaanalysis. Group Processes \& Intergroup Relations, 5(1): 35-52. 


\section{TABLES AND FIGURES}

\section{TABLE 1}

\section{Descriptive Statistics and Correlations for Variables in Study 1}

\begin{tabular}{|c|c|c|c|c|c|c|c|c|c|c|c|c|c|c|}
\hline Variables & $\mathbf{N}$ & Mean & SD & (1) & (2) & (3) & (4) & (5) & (6) & (7) & (8) & (9) & (10) & (11) \\
\hline 1. Extraversion & 198 & 2.64 & 0.77 & & & & & & & & & & & \\
\hline 2. Agreeable & 198 & 3.61 & 0.68 & $.29 * *$ & & & & & & & & & & \\
\hline 3. Conscientious & 198 & 3.35 & 0.83 & $.34 * *$ & $.40 * *$ & & & & & & & & & \\
\hline 4. Neurotic & 198 & 3.03 & 0.96 & $-.44 * *$ & $-.25 * *$ & $-.41 * *$ & & & & & & & & \\
\hline 5. Openness & 198 & 3.58 & 0.78 & $.36^{* *}$ & $.22 * *$ & $.17^{*}$ & $-.15^{*}$ & & & & & & & \\
\hline 6. Value claiming preference & 193 & 5.93 & 0.93 & -.06 & -.02 & .09 & .11 & .11 & & & & & & \\
\hline 7. Value creating preference & 198 & 4.41 & 1.56 & .07 & .09 & $.12 \dagger$ & $-.16^{*}$ & -.04 & -.11 & & & & & \\
\hline 8. Relationship preference & 198 & 4.82 & 1.41 & .09 & $.18 * *$ & .03 & .10 & .04 & .00 & .06 & & & & \\
\hline 9. Value claiming choice & 198 & 0.56 & 0.50 & -.03 & -.10 & -.01 & -.10 & .03 & $.38 * *$ & $-.33 * *$ & $-.24 * *$ & & & \\
\hline 10. Value creating choice & 198 & 0.18 & 0.39 & .01 & .05 & -.01 & .00 & -.02 & $-.21 * *$ & $.37 * *$ & -.09 & $-.53 * *$ & & \\
\hline 11. Relationship choice & 198 & 0.26 & 0.44 & .03 & .07 & .01 & .11 & -.02 & $-.25 * *$ & .05 & $.35^{* *}$ & $-.67 * *$ & $-.28 * *$ & \\
\hline 12. Female & 196 & 0.49 & 0.50 & .05 & $.25 * *$ & $.26 * *$ & $16^{*}$ & $.13 \dagger$ & .04 & $.14 \dagger$ & .08 & $-.16^{*}$ & .07 & $.12 \dagger$ \\
\hline
\end{tabular}

$$
\begin{array}{r}
\dagger p<.10 \\
* p<.05 \\
* * p<.01
\end{array}
$$


TABLE 2

The Effects of Personality and Gender on Information Preference

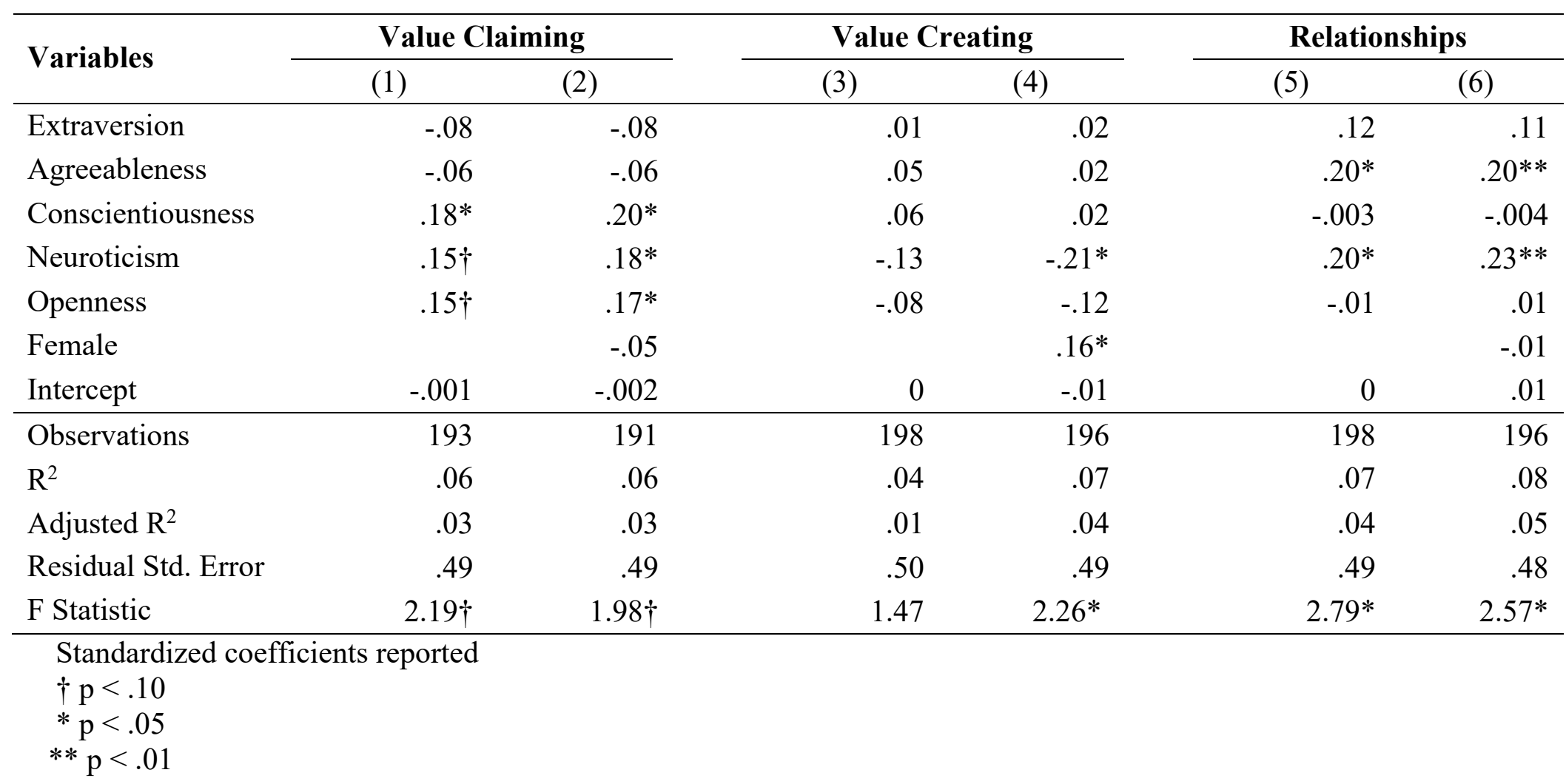


TABLE 3

The Effects of Personality and Gender on the Final Choice of Information

\begin{tabular}{|c|c|c|c|c|c|c|}
\hline \multirow{2}{*}{ Variables } & \multicolumn{2}{|c|}{ Value Claiming } & \multicolumn{2}{|c|}{ Value Creating } & \multicolumn{2}{|c|}{ Relationships } \\
\hline & (1) & (2) & (3) & (4) & $(5)$ & (6) \\
\hline Extraversion & .86 & .89 & .84 & .81 & 1.38 & 1.37 \\
\hline Agreeableness & .67 & .73 & .98 & .97 & 1.51 & 1.41 \\
\hline Conscientiousness & 1.08 & 1.24 & .86 & .86 & 1.07 & .94 \\
\hline Neuroticism & .83 & .96 & .72 & .71 & $1.66^{*}$ & $1.48 \dagger$ \\
\hline Openness & 1.18 & 1.18 & 1.04 & 1.07 & .82 & .79 \\
\hline Female & & .55 & & 1.07 & & 1.70 \\
\hline Intercept & 14.02 & 5.36 & 4.61 & 4.96 & $.02 *$ & $0.04 \dagger$ \\
\hline Reference Category & \multicolumn{2}{|c|}{ Value Creating } & \multicolumn{2}{|c|}{ Relationships } & \multicolumn{2}{|c|}{ Value Claiming } \\
\hline Observation & 198 & 198 & 198 & 198 & 198 & 198 \\
\hline Akaike Inf. Crit. & 406.46 & 403.23 & 406.46 & 403.23 & 406.46 & 403.23 \\
\hline $\begin{array}{r}\dagger p<.10 \\
* p<.05 \\
* * p<.01\end{array}$ & & & & & & \\
\hline
\end{tabular}


TABLE 4

Descriptive Statistics and Correlations for Variables in Study 2

\begin{tabular}{|c|c|c|c|c|c|c|c|c|c|c|c|c|c|c|c|c|}
\hline Variables & $\mathbf{N}$ & Mean & SD & (1) & (2) & (3) & (4) & (5) & (6) & (7) & (8) & (9) & (10) & (11) & (12) & (13) \\
\hline 1. Extraversion & 200 & 2.81 & 0.76 & & & & & & & & & & & & & \\
\hline 2. Agreeable & 200 & 3.66 & 0.65 & $.32 * *$ & & & & & & & & & & & & \\
\hline 3. Conscientious & 200 & 3.44 & 0.75 & $.29 * *$ & $.43 * *$ & & & & & & & & & & & \\
\hline 4. Neurotic & 200 & 2.92 & 0.92 & $-.47 * *$ & $-.41^{* *}$ & $-.41 * *$ & & & & & & & & & & \\
\hline 5. Openness & 200 & 3.64 & 0.77 & $.34 * *$ & $.19 * *$ & .01 & $-.15^{*}$ & & & & & & & & & \\
\hline 6. Female & 200 & 0.48 & 0.50 & -.04 & .02 & -.09 & $.23 * *$ & .01 & & & & & & & & \\
\hline 7. Duration value claiming & 196 & 22928.20 & 14345.41 & -.07 & $.14 *$ & .00 & -.06 & -.07 & .01 & & & & & & & \\
\hline 8. Duration value creating & 197 & 27896.23 & 17685.56 & $-.13 \dagger$ & .07 & .06 & -.06 & $-.20 * *$ & .06 & $.62^{* *}$ & & & & & & \\
\hline 9. Duration relationship & 196 & 27450.03 & 16577.49 & -.09 & $.12 \dagger$ & .03 & -.08 & -.05 & .07 & $.61^{* *}$ & $.62 * *$ & & & & & \\
\hline 10. Duration total & 195 & 77570.46 & 41413.17 & -.11 & $.14^{*}$ & .03 & -.08 & -.11 & .06 & $.84^{* *}$ & $.87^{* *}$ & $.87^{* *}$ & & & & \\
\hline 11. Click value claiming & 200 & 10.16 & 5.18 & $-.13 \dagger$ & .07 & -.07 & .00 & -.05 & .07 & $.73^{* *}$ & $.45^{* *}$ & $.45^{* *}$ & $.61^{* *}$ & & & \\
\hline 12. Click value creating & 200 & 10.27 & 6.21 & -.11 & .07 & -.05 & .03 & $-.17^{*}$ & .07 & $.53^{* *}$ & $.69^{* *}$ & $.48^{* *}$ & $.64 * *$ & $.68^{* *}$ & & \\
\hline 13. Click relationship & 200 & 10.85 & 6.11 & -.08 & .06 & -.02 & -.01 & -.07 & .01 & $.53^{* *}$ & $.50 * *$ & $.72 * *$ & $.65^{* *}$ & $.65^{* *}$ & $.76^{* *}$ & \\
\hline 14. Total click & 200 & 31.28 & 15.66 & $-.12 \dagger$ & .07 & -.05 & .01 & -.12 & .05 & $.65^{* *}$ & $.63^{* *}$ & $.63^{* *}$ & $.72 * *$ & $.86^{* *}$ & $.92 * *$ & $.91^{* *}$ \\
\hline
\end{tabular}


TABLE 5

Summary of the Frequency of Visits on Each Type of Information

\begin{tabular}{llcc}
\hline Category & Label & Number of Clicks & Pct \\
\hline Value claim 1 & Value of land & 1033 & $17 \%$ \\
Value claim 2 & Insurance value of building & 999 & $16 \%$ \\
\hline Value create 1 & Additional opportunities & 1028 & $16 \%$ \\
Value create 2 & Collaboration with Startech & 1028 & $16 \%$ \\
\hline Relationship 1 & Behavior in prior deals & 148 & $18 \%$ \\
Relationship 2 & Personality \& interests from interviews with & 1022 & $16 \%$ \\
& past coworkers & & \\
\hline
\end{tabular}


TABLE 6

The Effects of Personality and Gender on Time Spent on Each Category of Boxes

\begin{tabular}{|c|c|c|c|c|c|c|c|c|}
\hline \multirow{2}{*}{ Variables } & \multicolumn{2}{|c|}{ Value Claiming } & \multicolumn{2}{|c|}{ Value Creating } & \multicolumn{2}{|c|}{ Relationships } & \multicolumn{2}{|c|}{ Total Time } \\
\hline & (1) & (2) & (3) & (4) & (5) & (6) & (7) & (8) \\
\hline Extraversion & -.12 & -.13 & $-.16 \dagger$ & $-.16 \dagger$ & $-.17 \dagger$ & $-.17 *$ & $-.19 *$ & $-.19 *$ \\
\hline Agreeableness & $.20 *$ & $.19^{*}$ & .11 & .09 & $.15 \dagger$ & .13 & $.19 *$ & $.17 *$ \\
\hline Conscientiousness & -.09 & -.09 & .01 & .02 & -.02 & -.02 & -.04 & -.04 \\
\hline Neuroticism & -.09 & -.09 & -.11 & -.14 & -.11 & -.13 & -.13 & $-.15 \dagger$ \\
\hline Openness & -.07 & -.07 & $-.18 *$ & $-.18^{*}$ & -.04 & -.04 & -.10 & -.10 \\
\hline Observations & 196 & 196 & 197 & 197 & 196 & 196 & 195 & 195 \\
\hline $\mathrm{R}^{2}$ & .05 & .05 & .07 & .08 & .04 & .05 & .07 & .07 \\
\hline Adjusted $\mathrm{R}^{2}$ & .02 & .02 & .05 & .05 & .02 & .02 & .04 & .04 \\
\hline Residual Std. Error & .49 & .50 & .49 & .49 & .50 & .50 & .49 & .49 \\
\hline F Statistic & $1.91 \dagger$ & 1.59 & $2.91 *$ & $2.67 *$ & 1.66 & 1.62 & $2.72 *$ & $2.50 *$ \\
\hline
\end{tabular}

Standardized coefficients reported

$\uparrow \mathrm{p}<.10$

$* \mathrm{p}<.05$

$* * \mathrm{p}<.01$ 
TABLE 7

The Effects of Personality and Gender on the Frequency of Visits on Each Category of Information

\begin{tabular}{|c|c|c|c|c|c|c|c|c|}
\hline \multirow{2}{*}{ Variables } & \multicolumn{2}{|c|}{ Value Claiming } & \multicolumn{2}{|c|}{ Value Creating } & \multicolumn{2}{|c|}{ Relationships } & \multicolumn{2}{|c|}{ Total Click } \\
\hline & (1) & (2) & (3) & (4) & (5) & (6) & (7) & $(8)$ \\
\hline Extraversion & $.89^{*}$ & $.89 *$ & .94 & .94 & .93 & .93 & .92 & .92 \\
\hline Agreeableness & $1.13 \dagger$ & $1.12 \dagger$ & $1.18^{*}$ & $1.17^{*}$ & 1.10 & 1.09 & $1.13^{*}$ & $1.13 \dagger$ \\
\hline Conscientiousness & .93 & .93 & 0.91 & .92 & .96 & .96 & .93 & .93 \\
\hline Neuroticism & .97 & .96 & 1.00 & .99 & .97 & .97 & .98 & .97 \\
\hline Openness & .98 & .97 & $.86^{* *}$ & $.86^{* *}$ & .96 & .96 & .93 & .93 \\
\hline Observations & 200 & 200 & 200 & 200 & 200 & 200 & 200 & 200 \\
\hline Log Likelihood & -600.36 & -599.98 & -615.02 & -614.66 & -623.62 & -623.62 & -809 & -808.81 \\
\hline$\theta$ & $6.61 * *$ & $6.66^{* *}$ & $4.82 * *$ & $4.85 * *$ & $5.07 * *$ & $5.07 * *$ & $5.24 * *$ & $5.25 * *$ \\
\hline Akaike Inf. Crit. & 1212.71 & 1213.97 & 1242.04 & 1243.31 & 1259.24 & 1261.24 & 1629.99 & 1631.61 \\
\hline
\end{tabular}


TABLE 8

The Effects of Personality and Gender on the Final Choice of Information

\begin{tabular}{|c|c|c|c|c|c|c|}
\hline \multirow{2}{*}{ Variables } & \multicolumn{2}{|c|}{ Value Claiming } & \multicolumn{2}{|c|}{ Value Creating } & \multicolumn{2}{|c|}{ Relationships } \\
\hline & (1) & (2) & (3) & (4) & (5) & (6) \\
\hline Extraversion & .72 & .72 & 1.31 & 1.29 & 1.06 & 1.08 \\
\hline Agreeableness & .74 & .76 & 1.37 & 1.28 & .98 & 1.03 \\
\hline Conscientiousness & .76 & .76 & 1.40 & 1.43 & .94 & .92 \\
\hline Neuroticism & $0.62 \dagger$ & .64 & 1.46 & 1.31 & 1.11 & 1.18 \\
\hline Openness & $1.80 *$ & $1.81 *$ & $.57 *$ & $.57 *$ & .97 & .98 \\
\hline Female & & .82 & & 1.83 & & .67 \\
\hline Intercept & 13.57 & 12.04 & .07 & .09 & 1.07 & .91 \\
\hline Reference Category & \multicolumn{2}{|c|}{ Value Creating } & \multicolumn{2}{|c|}{ Relationships } & \multicolumn{2}{|c|}{ Value Claiming } \\
\hline Observation & 200 & 200 & 200 & 200 & 200 & 200 \\
\hline Akaike Inf. Crit. & 445.16 & 446.37 & 445.16 & 446.37 & 445.16 & 446.37 \\
\hline
\end{tabular}


TABLE 9

Descriptive Statistics and Correlations for Variables in Study 3

\begin{tabular}{|c|c|c|c|c|c|c|c|c|c|c|c|c|c|c|c|c|}
\hline Variables & $\mathbf{N}$ & Mean & SD & (1) & (2) & (3) & (4) & (5) & (6) & (7) & (8) & (9) & (10) & (11) & (12) & (13) \\
\hline 1. Extraversion & 298 & 2.75 & 0.74 & & & & & & & & & & & & & \\
\hline 2. Agreeable & 298 & 3.59 & 0.68 & $.16^{* *}$ & & & & & & & & & & & & \\
\hline 3. Conscientious & 298 & 3.33 & 0.83 & $.31 * *$ & $.43 * *$ & & & & & & & & & & & \\
\hline 4. Neurotic & 298 & 2.98 & 0.93 & $-.29 * *$ & $-.22 * *$ & $-.46^{* *}$ & & & & & & & & & & \\
\hline 5. Openness & 298 & 3.74 & 0.77 & $.21 * *$ & .04 & -.02 & .05 & & & & & & & & & \\
\hline 6. Female & 298 & 0.44 & 0.50 & .00 & $.13^{*}$ & .02 & $.20 * *$ & $.10 \dagger$ & & & & & & & & \\
\hline 7. Duration value claiming & 295 & 7445.54 & 8945.64 & .03 & .08 & $.10 \dagger$ & -.09 & .04 & -.07 & & & & & & & \\
\hline 8. Duration value creating & 291 & 8838.01 & 8821.97 & -.06 & .00 & .01 & -.08 & $-.14 *$ & -.08 & $-.27 * *$ & & & & & & \\
\hline 9. Duration relationship & 293 & 9727.46 & 8332.99 & -.01 & .00 & -.05 & -.04 & .04 & .01 & $-.19 * *$ & $.15^{* *}$ & & & & & \\
\hline 10. Duration total & 294 & 27112.64 & 14405.43 & -.02 & .08 & .04 & $-.12 *$ & -.01 & .01 & $.29 * *$ & $.56^{* *}$ & $.52 * *$ & & & & \\
\hline 11. Click value claiming & 298 & 1.76 & 1.77 & .05 & .08 & $.10 \dagger$ & -.07 & .02 & -.09 & $.75 * *$ & $-.48 * *$ & $-.44 * *$ & -.09 & & & \\
\hline 12. Click value creating & 298 & 2.03 & 1.58 & -.05 & -.09 & -.05 & .01 & -.07 & .03 & $-.47 * *$ & $.76^{* *}$ & -.10 & $.15^{*}$ & $-.61 * *$ & & \\
\hline 13. Click relationship & 298 & 2.08 & 1.50 & .01 & -.03 & -.08 & .09 & .03 & $.10 \dagger$ & $-.37 * *$ & $-.19 * *$ & $.69^{* *}$ & .01 & $-.52 * *$ & $-.31 * *$ & \\
\hline 14. Total click & 298 & 5.87 & 0.53 & .02 & -.09 & -.01 & .04 & -.07 & .06 & .08 & $.12 *$ & $.17^{* *}$ & $.17^{* *}$ & .08 & .08 & $.18^{* *}$ \\
\hline
\end{tabular}


TABLE 10

Descriptive Statistics and Correlations for Variables in Study 3

\begin{tabular}{llcc}
\hline Category & Label & Number of Clicks & Pct \\
\hline Value claim 1 & Value of land & 331 & $19 \%$ \\
Value claim 2 & Insurance value of building & 194 & $11 \%$ \\
\hline Value create 1 & Additional opportunities & 161 & $9 \%$ \\
Value create 2 & Collaboration with Startech & 443 & $25 \%$ \\
\hline Relationship 1 & Behavior in prior deals & 499 & $29 \%$ \\
Relationship 2 & Personality \& interests from interviews with & 120 & $7 \%$ \\
& past coworkers & & \\
\hline
\end{tabular}




\section{TABLE 11}

The Effects of Personality and Gender on Time Spent on Each Category of Boxes in Study 3

\begin{tabular}{|c|c|c|c|c|c|c|c|c|}
\hline \multirow{2}{*}{ Variables } & \multicolumn{2}{|c|}{ Value Claiming } & \multicolumn{2}{|c|}{ Value Creating } & \multicolumn{2}{|c|}{ Relationships } & \multicolumn{2}{|c|}{ Total Time } \\
\hline & (1) & (2) & (3) & (4) & $(5)$ & (6) & (7) & $(8)$ \\
\hline Extraversion & -.02 & -.02 & -.05 & -.05 & -.02 & -.02 & -.06 & -.06 \\
\hline Agreeableness & .04 & .05 & .01 & .01 & .02 & .01 & .07 & .07 \\
\hline Conscientiousness & .07 & .07 & -.03 & -.03 & -.09 & -.09 & -.05 & -.05 \\
\hline Neuroticism & -.06 & -.04 & -.10 & -.09 & -.09 & -.09 & $-.14 *$ & $-.15^{*}$ \\
\hline Openness & .05 & .05 & $-.13 *$ & $-.12 *$ & .05 & .04 & .01 & .00 \\
\hline Female & & -.07 & & -.05 & & .02 & & .02 \\
\hline Intercept & .00 & .00 & .00 & .00 & .00 & -.00 & .00 & .00 \\
\hline Observations & 295 & 295 & 291 & 291 & 293 & 293 & 294 & 294 \\
\hline $\mathrm{R}^{2}$ & .02 & .02 & .03 & .03 & .01 & .01 & .02 & .02 \\
\hline Adjusted $\mathrm{R}^{2}$ & -.00 & .00 & .01 & .01 & -.01 & -.01 & .01 & .00 \\
\hline Residual Std. Error & .50 & .50 & .50 & .50 & .50 & .50 & .50 & .50 \\
\hline F Statistic & .97 & 1.05 & 1.64 & 1.48 & .59 & .51 & 1.30 & 1.11 \\
\hline
\end{tabular}

Standardized coefficients reported

$\dagger \mathrm{p}<.10$

$* \mathrm{p}<.05$

$* * \mathrm{p}<.01$ 
TABLE 12

The Effects of Personality and Gender on the Frequency of Visits on Each Category of Information in Study 3

\begin{tabular}{|c|c|c|c|c|c|c|}
\hline \multirow{2}{*}{ Variables } & \multicolumn{2}{|c|}{ Value Claiming } & \multicolumn{2}{|c|}{ Value Creating } & \multicolumn{2}{|c|}{ Relationships } \\
\hline & (1) & (2) & (3) & (4) & (5) & (6) \\
\hline Extraversion & 1.00 & 1.01 & .97 & .97 & 1.04 & 1.04 \\
\hline Agreeableness & 1.06 & 1.09 & .91 & .90 & 1.00 & .98 \\
\hline Conscientiousness & 1.09 & 1.09 & .99 & .98 & .95 & .95 \\
\hline Neuroticism & .96 & .99 & .98 & .97 & 1.06 & 1.04 \\
\hline Openness & 1.03 & 1.04 & .94 & .93 & 1.02 & 1.01 \\
\hline Female & & .81 & & 1.09 & & 1.14 \\
\hline Intercept & 1.09 & .92 & $4.25 * *$ & $4.52 * *$ & 1.72 & 1.89 \\
\hline Observations & 298 & 298 & 298 & 298 & 298 & 298 \\
\hline Log Likelihood & -536.67 & -535.48 & -543.56 & -543.19 & -529.21 & -528.09 \\
\hline$\theta$ & $1.41 * *$ & $1.44 * *$ & $6.53 *$ & $6.64^{*}$ & 28.43 & 32.47 \\
\hline Akaike Inf. Crit. & 1085.33 & 1084.95 & 1099.12 & 1100.38 & 1070.43 & 1070.18 \\
\hline
\end{tabular}


TABLE 13

The Effects of Personality and Gender on the Final Choice of Information in Study 3

\begin{tabular}{|c|c|c|c|c|c|c|}
\hline \multirow{2}{*}{ Variables } & \multicolumn{2}{|c|}{ Value Claiming } & \multicolumn{2}{|c|}{ Value Creating } & \multicolumn{2}{|c|}{ Relationships } \\
\hline & (1) & (2) & (3) & (4) & $(5)$ & (6) \\
\hline Extraversion & 1.19 & 1.20 & .84 & .84 & .99 & .99 \\
\hline Agreeableness & 1.25 & 1.31 & .92 & .90 & .86 & .85 \\
\hline Conscientiousness & 1.07 & 1.09 & 1.10 & 1.09 & .85 & .84 \\
\hline Neuroticism & .90 & .94 & 1.03 & 1.00 & 1.09 & 1.07 \\
\hline Openness & $1.44 \dagger$ & $1.47 \dagger$ & $.66^{*}$ & $.65^{*}$ & 1.06 & 1.05 \\
\hline Female & & .70 & & 1.23 & & 1.16 \\
\hline Intercept & $.08 \dagger$ & $.06 \dagger$ & 5.75 & 6.77 & 2.05 & 2.30 \\
\hline Reference Category & \multicolumn{2}{|c|}{ Value Creating } & \multicolumn{2}{|c|}{ Relationships } & \multicolumn{2}{|c|}{ Value Claiming } \\
\hline Observation & 298 & 298 & 298 & 298 & 298 & 298 \\
\hline Akaike Inf. Crit. & 665.21 & 667.86 & 665.21 & 667.86 & 665.21 & 667.86 \\
\hline
\end{tabular}


TABLE 14

Descriptive Statistics and Correlations for Variables in Study 4

\begin{tabular}{|c|c|c|c|c|c|c|c|c|c|c|c|c|c|c|c|c|}
\hline Variables & $\mathbf{N}$ & Mean & SD & (1) & (2) & (3) & (4) & (5) & (6) & (7) & (8) & (9) & (10) & (11) & (12) & (13) \\
\hline 1. Extraversion & 288 & 2.70 & 0.81 & & & & & & & & & & & & & \\
\hline 2. Agreeable & 288 & 3.59 & 0.71 & $.22 * *$ & & & & & & & & & & & & \\
\hline 3. Conscientious & 288 & 3.37 & 0.82 & $.42 * *$ & $.40 * *$ & & & & & & & & & & & \\
\hline 4. Neurotic & 288 & 2.97 & 0.96 & $-.45 * *$ & $-.18 * *$ & $-.36 * *$ & & & & & & & & & & \\
\hline 5. Openness & 288 & 3.64 & 0.74 & .09 & .09 & .01 & -.03 & & & & & & & & & \\
\hline 6. Female & 288 & 0.43 & 0.50 & -.03 & $.11 \dagger$ & $.19 * *$ & $.21 * *$ & .01 & & & & & & & & \\
\hline 7. Duration value claiming & 281 & 5544.52 & 5776.04 & .09 & .03 & $.11 \dagger$ & $-.12 \dagger$ & $-.11 \dagger$ & .01 & & & & & & & \\
\hline 8. Duration value creating & 283 & 7628.04 & 6019.22 & -.07 & .08 & .04 & .07 & -.03 & .09 & $-.31 * *$ & & & & & & \\
\hline 9. Duration relationship & 286 & 8546.30 & 7294.93 & -.07 & .03 & .07 & .06 & .02 & .05 & -.10 & $.17 * *$ & & & & & \\
\hline 10. Duration total & 282 & 22019.97 & 10749.04 & .01 & .07 & $.11 \dagger$ & .01 & -.07 & .08 & $.27 * *$ & $.49 * *$ & $.70 * *$ & & & & \\
\hline 11. Click value claiming & 288 & 1.58 & 1.30 & $.11 \dagger$ & -.02 & .02 & $-.12 *$ & -.05 & -.08 & $.77^{* *}$ & $-.46 * *$ & $-.31 * *$ & -.05 & & & \\
\hline 12. Click value creating & 288 & 2.06 & 1.18 & $-.10 \dagger$ & .02 & -.02 & .03 & .02 & .04 & $-.52 * *$ & $.63^{* *}$ & -.09 & .01 & $-.64 * *$ & & \\
\hline 13. Click relationship & 288 & 2.24 & 1.04 & -.03 & -.04 & -.02 & $.11 \dagger$ & .02 & .02 & $-.34 * *$ & $-.10 \dagger$ & $.54 * *$ & $.13 *$ & $-.47 * *$ & $-.26 * *$ & \\
\hline 14. Total click & 288 & 5.88 & 0.54 & -.03 & -.08 & -.03 & -.01 & -.05 & -.06 & .04 & .07 & .09 & $.15 *$ & $.12 *$ & $.14^{*}$ & $.22 * *$ \\
\hline
\end{tabular}


TABLE 15

Summary of the Frequency of Visits on Each Type of Information in Study 4

\begin{tabular}{llcc}
\hline Category & Label & Number of Clicks & Pct \\
\hline Value claim 1 & Value of land & 461 & $27 \%$ \\
\hline Value create 2 & Collaboration with Startech & 596 & $35 \%$ \\
\hline Relationship 1 & Behavior in prior deals & 645 & $38 \%$ \\
\hline
\end{tabular}


TABLE 16

The Effects of Personality and Gender on Time Spent on Each Category of Boxes in Study 4

\begin{tabular}{|c|c|c|c|c|c|c|c|c|}
\hline \multirow{2}{*}{ Variables } & \multicolumn{2}{|c|}{ Value Claiming } & \multicolumn{2}{|c|}{ Value Creating } & \multicolumn{2}{|c|}{ Relationships } & \multicolumn{2}{|c|}{ Total Time } \\
\hline & $(1)$ & $(2)$ & (3) & (4) & $(5)$ & $(6)$ & (7) & $(8)$ \\
\hline Extraversion & .04 & .04 & -.09 & -.09 & -.09 & -.09 & -.03 & -.03 \\
\hline Agreeableness & -.01 & -.01 & .09 & .09 & .01 & .01 & .04 & .04 \\
\hline Conscientiousness & .07 & .06 & .06 & .05 & $.13 \dagger$ & $.13 \dagger$ & $.13 \dagger$ & .11 \\
\hline Neuroticism & -.08 & -.09 & .07 & .05 & .07 & .07 & .05 & .03 \\
\hline Openness & $-.12 \dagger$ & $-.12 \dagger$ & -.03 & -.03 & .03 & .03 & -.07 & -.07 \\
\hline Female & & .02 & & .06 & & .01 & & .05 \\
\hline Intercept & .00 & .00 & .00 & .00 & .00 & .00 & .00 & .00 \\
\hline Observations & 281 & 281 & 283 & 283 & 286 & 286 & 282 & 282 \\
\hline $\mathrm{R}^{2}$ & .03 & .03 & .02 & .02 & .02 & .02 & .02 & .02 \\
\hline Adjusted $\mathrm{R}^{2}$ & .01 & .01 & .00 & .00 & .00 & -.00 & .01 & .00 \\
\hline Residual Std. Error & .50 & .50 & .50 & .50 & .50 & .50 & .50 & .50 \\
\hline F Statistic & 1.82 & 1.54 & 1.24 & 1.16 & 1.18 & .98 & 1.30 & 1.18 \\
\hline
\end{tabular}

Standardized coefficients reported

$\dagger \mathrm{p}<.10$

$* \mathrm{p}<.05$

$* * \mathrm{p}<.01$ 
TABLE 17

The Effects of Personality and Gender on the Frequency of Visits on Each Category of Information in Study 4

\begin{tabular}{|c|c|c|c|c|c|c|}
\hline \multirow{2}{*}{ Variables } & \multicolumn{2}{|c|}{ Value Claiming } & \multicolumn{2}{|c|}{ Value Creating } & \multicolumn{2}{|c|}{ Relationships } \\
\hline & (1) & (2) & (3) & (4) & (5) & (6) \\
\hline Extraversion & 1.09 & 1.09 & .91 & .91 & 1.01 & 1.01 \\
\hline Agreeableness & .95 & .96 & 1.03 & 1.03 & .98 & .98 \\
\hline Conscientiousness & .96 & .98 & 1.01 & 1.00 & 1.02 & 1.02 \\
\hline Neuroticism & .92 & .93 & .99 & .99 & 1.06 & 1.06 \\
\hline Openness & .94 & .94 & 1.02 & 1.02 & 1.02 & 1.02 \\
\hline Female & & .92 & & 1.05 & & 1.00 \\
\hline Intercept & $2.72 *$ & $2.55^{*}$ & $2.16^{*}$ & $2.24 *$ & 1.77 & 1.77 \\
\hline Observations & 288 & 288 & 288 & 288 & 288 & 288 \\
\hline Log Likelihood & -462.09 & -461.73 & -465.92 & -465.78 & -453.34 & -453.34 \\
\hline Akaike Inf. Crit. & 936.17 & 937.47 & 943.84 & 945.57 & 918.67 & 920.67 \\
\hline $\begin{array}{r}\dagger p<.10 \\
* p<.05 \\
* * p<.01\end{array}$ & & & & & & \\
\hline
\end{tabular}


TABLE 18

The Effects of Personality and Gender on the Final Choice of Information in Study 4

\begin{tabular}{|c|c|c|c|c|c|c|}
\hline \multirow{2}{*}{ Variables } & \multicolumn{2}{|c|}{ Value Claiming } & \multicolumn{2}{|c|}{ Value Creating } & \multicolumn{2}{|c|}{ Relationships } \\
\hline & (1) & (2) & (3) & (4) & $(5)$ & (6) \\
\hline Extraversion & 1.02 & 1.01 & 1.37 & 1.37 & .71 & .72 \\
\hline Agreeableness & .82 & .83 & 1.14 & 1.14 & 1.08 & 1.06 \\
\hline Conscientiousness & 1.00 & 1.06 & .81 & .83 & 1.23 & 1.13 \\
\hline Neuroticism & .74 & .78 & 1.12 & 1.16 & 1.20 & 1.11 \\
\hline Openness & .93 & .93 & .95 & .95 & 1.14 & 1.14 \\
\hline Female & & .74 & & .82 & & 1.64 \\
\hline Intercept & 4.21 & 3.33 & .35 & .30 & .68 & 1.00 \\
\hline Reference Category & \multicolumn{2}{|c|}{ Value Creating } & \multicolumn{2}{|c|}{ Relationships } & \multicolumn{2}{|c|}{ Value Claiming } \\
\hline Observation & 288 & 288 & 288 & 288 & 288 & 288 \\
\hline Akaike Inf. Crit. & 627.42 & 629.26 & 627.42 & 629.26 & 627.42 & 629.26 \\
\hline $\begin{array}{r}\dagger p<.10 \\
* p<.05 \\
* * p<.01\end{array}$ & & & & & & \\
\hline
\end{tabular}


FIGURE 1

Mouselab's Information Grid Cover in Study 2

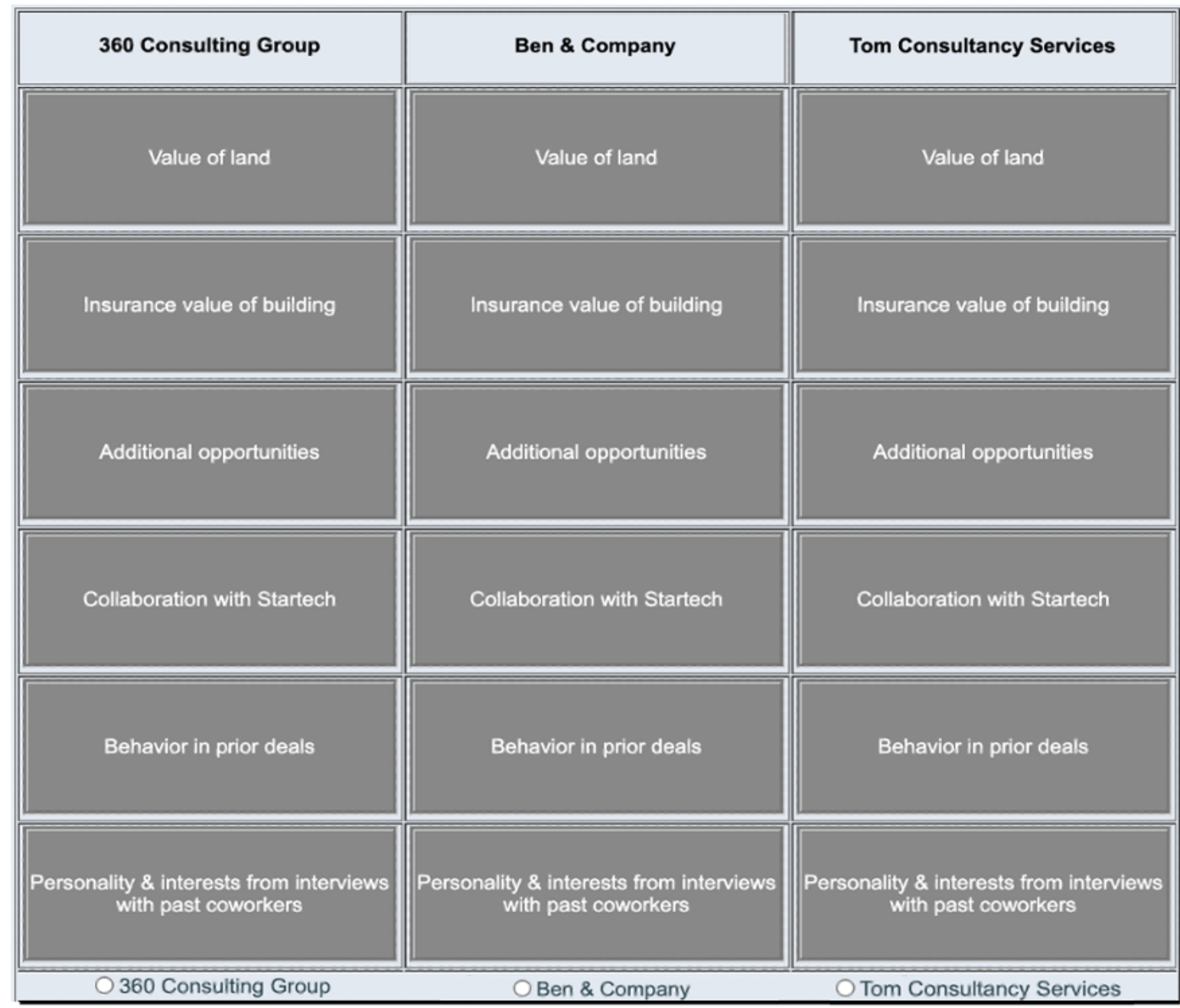


FIGURE 2

Mouselab's Information Grid Contents in Study 2

\begin{tabular}{|c|c|c|}
\hline 360 Consulting Group & Ben \& Company & Tom Consultancy Services \\
\hline $\begin{array}{l}360 \text { Consulting Group can provide } \\
\text { you with the most recent market } \\
\text { valuation of the land where } \\
\text { Startech's plant is located. }\end{array}$ & $\begin{array}{l}\text { Ben \& Company does not have } \\
\text { enough reliable data to estimate the } \\
\text { most recent market valuation of the } \\
\text { land where Startech's plant is } \\
\text { located. }\end{array}$ & $\begin{array}{c}\text { Tom Consultancy Services does not } \\
\text { conduct research on real estate } \\
\text { value. }\end{array}$ \\
\hline $\begin{array}{l}360 \text { Consulting Group can provide } \\
\text { you with an accurate insurance } \\
\text { value of the Startech's plant } \\
\text { including building and equipment. }\end{array}$ & $\begin{array}{l}\text { Ben \& Company do not have people } \\
\text { who can estimate the value of } \\
\text { equipment or the building on } \\
\text { Startech's plant. }\end{array}$ & $\begin{array}{l}\text { Tom Consultancy Services does not } \\
\text { have any reliable information to } \\
\text { estimate the insurance value of the } \\
\text { Startech's plant. }\end{array}$ \\
\hline $\begin{array}{l}360 \text { Consulting Group does not } \\
\text { have information about products or } \\
\text { services that Startech would be } \\
\text { interested in. }\end{array}$ & $\begin{array}{l}\text { Ben \& Company has information } \\
\text { about products and services } \\
\text { Startech should be interested in } \\
\text { purchasing from your company. }\end{array}$ & $\begin{array}{l}\text { Due to a confidentiality agreement, } \\
\text { Tom Consultancy Services cannot } \\
\text { reveal any information about } \\
\text { Startech's needs. }\end{array}$ \\
\hline $\begin{array}{l}360 \text { Consulting Group does not } \\
\text { have any information regarding } \\
\text { opportunities for cooperation with } \\
\text { Startech. }\end{array}$ & $\begin{array}{c}\text { As a former consultant for Startech, } \\
\text { Ben \& Company can give you some } \\
\text { insights into potential collaborative } \\
\text { project with Startech. }\end{array}$ & $\begin{array}{l}\text { Tom Consultancy Services does not } \\
\text { have any specialists who are } \\
\text { knowledgeable about current } \\
\text { projects at Startech. }\end{array}$ \\
\hline $\begin{array}{l}360 \text { Consulting Group has no prior } \\
\text { experience in interacting with the } \\
\text { Startech CFO or Startech's behavior } \\
\text { in prior negotiations. }\end{array}$ & $\begin{array}{l}\text { No-one at Ben \& Company has } \\
\text { worked with the current CFO of } \\
\text { Startech or their current group of } \\
\text { negotiators. }\end{array}$ & $\begin{array}{l}\text { Tom Consultancy Services has } \\
\text { negotiated with the Startech CFO in } \\
\text { the past, and can advise you on his } \\
\text { negotiating style. }\end{array}$ \\
\hline $\begin{array}{l}360 \text { Consulting Group does not } \\
\text { have information about Startech } \\
\text { CFO's reputation among co-workers } \\
\text { and peers. }\end{array}$ & $\begin{array}{l}\text { Ben \& Company has not conducted } \\
\text { interviews with colleagues and } \\
\text { employees of the Startech CFO. }\end{array}$ & $\begin{array}{l}\text { Tom Consultancy Services has } \\
\text { industry contacts who can tell you } \\
\text { about the Startech CFO's reputation } \\
\text { as a negotiator, personality, and } \\
\text { their interests in life. }\end{array}$ \\
\hline 360 Consulting Group & Ben \& Company & Tom Consultancy Services \\
\hline
\end{tabular}


FIGURE 3

Mouselab's Information Grid Cover in Study 4

\begin{tabular}{|c|c|c|}
\hline 360 Consulting Group & Ben \& Company & Tom Consultancy Services \\
\hline Value of land & Value of land & Value of land \\
\hline Collaboration with Startech & Collaboration with Startech & Collaboration with Startech \\
\hline Behavior in prior deals & Behavior in prior deals & Behavior in prior deals \\
\hline 360 Consulting Group & Ben \& Company & Tom Consultancy Servic \\
\hline
\end{tabular}

